\title{
Polysaccharides as safer release systems for agrochemicals
}

\author{
Estefânia Vangelie Ramos Campos • Jhones Luiz de \\ Oliveira $\cdot$ Leonardo Fernandes Fraceto $\cdot$ Baljit Singh
}

Accepted: 13 October 2014 / Published online: 14 November 2014

(C) INRA and Springer-Verlag France 2014
Keywords Polysaccharides $\cdot$ Slow release formulations · Pesticides $\cdot$ Agrochemical

\section{Contents}

1. Introduction ...........................

2. Controlled-release agrochemical delivery systems

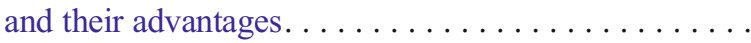

3. Polymer-based controlled-release agrochemical delivery systems/ formulations . . . . . . . . . . .

4. Classifications of controlled-release agrochemical delivery systems. . . . . . . . . . . . . . .

5. Commonly used biopolymers for agrochemical delivery systems. . . . . . . . . . . . . . . .

6. Polysaccharide-based controlled-release formulation in the form of microspheres

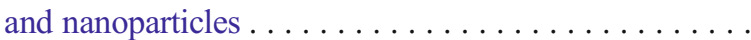

7. Polysaccharide-based controlled-release formulation in the form of beads and polymeric networks/hydrogels . . . . . . . . . . . .

8. Cyclodextrins as carrier system to agrochemicals .....

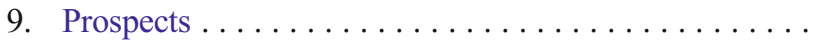

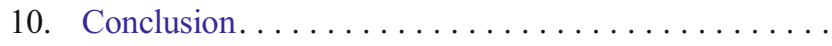

Conflict of interest. . . . . . . . . . . . . . . . .

Acknowledgments . . . . . . . . . . . . . . .

References.........................

\section{Introduction}

Global demand for food due to the increase of the world population has encouraged the maximization of agricultural production, thus has sought the development of high-value crops, which include the use of pesticides, fertilizers, and 
equipment with high technology (Popp et al. 2013; Campos et al. 2014).

Agrochemicals play a major role, in order to maintain the increasing demand of food to the growing population. However, harmful effect of these chemicals to the environment and health is a major limitation on their use. Hence, safe handling of these chemicals is also very significant (Abhilash and Singh 2009). Agrochemical is a generic term for the various chemical products used in agriculture including pesticides, chemical fertilizers, manure, and other growth agents. Among these chemicals, pesticides play a very important role in agricultural development by controlling the pests because more than 30 $40 \%$ of the food production is lost due to pests (Swinnen et al. 2000)

In the conventional formulations, the active ingredient is mixed with other inert materials for their safer, easier, and more accurate handling as well as for their effective application in the field. However, the immediate release of active ingredient is the main drawback associated with these formulations. Consequently, quick loss of these chemicals occurs from the field by various degradation processes including photolytic degradation, hydrolytic degradation, and microbial degradation. These are also lost by volatilization, evaporation, and leaching that occur after their application to field. As a result, concentration of active agent in the field decreases very quickly, below the minimum effective concentration required to maintain the biological efficacy. In order to maintain their concentration to the desired level, these chemicals need to be applied again and again that leads to various environmental and health problems. The excess quantity of pesticides sometimes may cause phytotoxicity. Recently, new formulations have been developed that may modify performance of active compound which have less impact on environment (Fig. 1). These formulations release the chemicals slowly in controlled and sustained manner (Scher 1999; Campos et al. 2014).

\section{Controlled-release agrochemical delivery systems and their advantages}

In a controlled-release system or controlled-release formulations, a pesticide or other bioactive agent is incorporated into a carrier, generally a polymeric material. These systems are capable of delivering active ingredient slowly and continuously for longer duration to a specified target at a desired rate (Fig. 2). They minimize the impact of these harmful chemicals on the environment by reducing losses due to leaching, volatilization, and degradation and thereby maintaining biological efficacy of active ingredient (Nair et al. 2010; Gogos et al. 2012; Campos et al. 2014).

The encapsulation of pesticides has been reported to enhance their safety and handling aspects. The more volatilized and flammable liquid pesticides can be converted to solid polymeric formulations that make their transportation easy and reduce chances of inflammation and evaporation (Tsuji 2001). In one study, it is reported that the mobility of imidacloprid insecticide in soil from alginate-based controlled-release system decreased in vertical mobility of insecticide from this system $(44.7 \%)$ as compared to technical product $(82.3 \%)$. The volatilization of active ingredient has also been reported to reduce with the use of polymeric systems (Dailey 2004). In some agricultural application, e.g., seed treatment, the initial release of pesticide is not desirable as it can harm the germinating seed itself. Due to autocatalytic hydrolysis of poly lactic acid, it has been used to develop the delayed release formulations (Zhao and Wilkins 2005). It can be attributed mainly to residual pesticide in soils. Since controlled-release systems would not release the AI at once, this therefore lowers the pesticide residues in soil and thus reduces the phytotoxicity (Mogul et al. 1996).

Recently, many efforts have been made to develop pesticides delivery devices by using different materials. These materials include polymers (Kumar et al. 2014; Paradelo et al. 2014; Chowdhury 2014), silica (Qian et al. 2013; Wanyika 2013; Zhang et al. 2014b), polyphosphates (Cini et al. 2012), waxes (Rodrigues et al. 2014), clay/organo-clay (Hickey et al. 2011; Sahoo et al. 2014), agro wastes (Petruccioli et al. 2011). However, the materials used to prepare release systems should satisfy the some requirements related to the diffusion/solubility/degradation/fabrications. The polymers in general have all the characteristics required to develop the controlled-release formulations (Price et al. 2014).

\section{Polymer-based controlled-release agrochemical delivery systems/formulations}

Polymers, especially in the form of hydrogels and beads, are very important in formation of controlled-release systems. These formulations, besides providing the slow-release profile to the pesticide, also increase the water-holding capacity of soil (Roy et al. 2014). After their degradation, these are helpful as compost in the field (Kumar et al. 2014). Natural polymers are gaining considerable acceptance over synthetic polymers as controlled-release devices because of their eco-friendly nature, cost effectiveness, easy availability, and biodegradability (Azwa et al. 2013).

\section{Classifications of controlled-release agrochemical delivery systems}

Based on the concept of combining pesticide with polymer matrices, these systems are broadly classified as physical and chemical combinations. The polymer acts as a rate-controlling 
Fig. 1 Schematic representation of the use of active agent in agriculture, as well as some of the problems related to the use of these compounds in the environment and as an alternative to solve these problems the use of controlled release systems

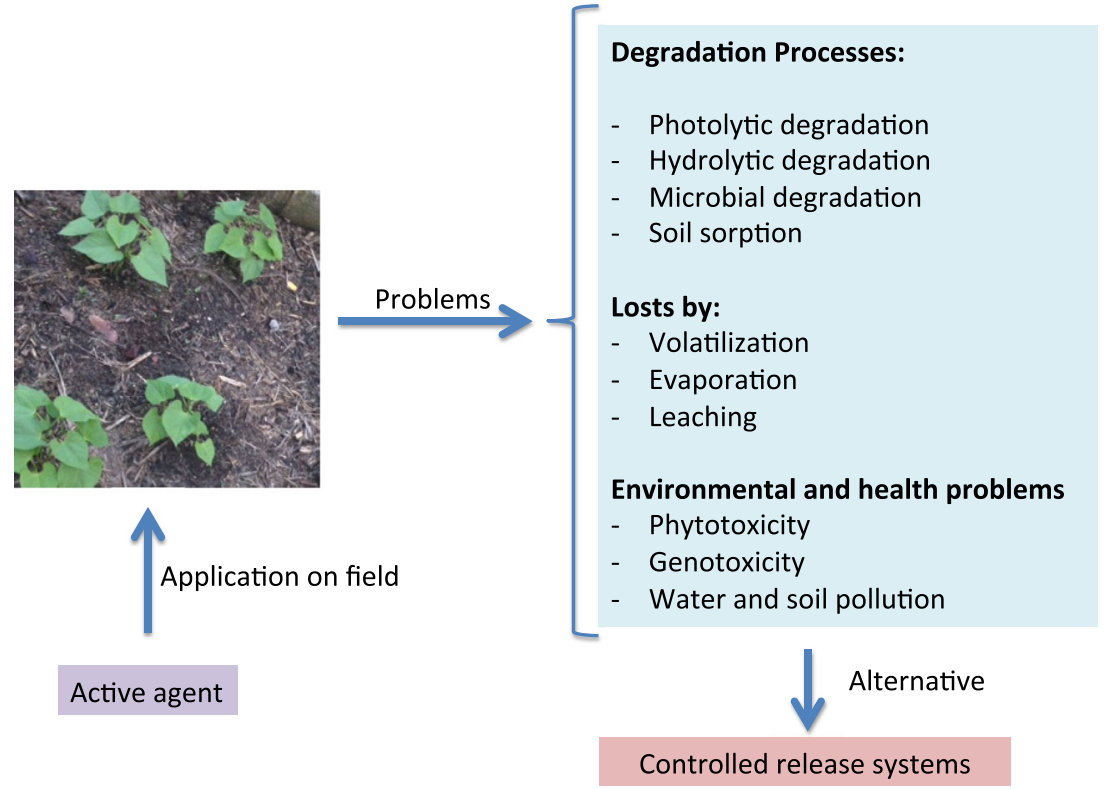

core material in gelatin (Mohanty and Bohidar 2003). In ionotropic gelation, pesticide containing polymer solution is poured drop wise into solution of metal ions. For example, solution of sodium alginate and pesticide added drop-wise into calcium chloride solution.

Another way to achieve the controlled-release pesticide formulations is by chemically attaching the active agent to natural or synthetic polymeric materials through a labile link, to regenerate the pesticide by hydrolysis or by enzymatic degradation (Kenawy 1998). These formulations especially
Fig. 2 Representation of a delivery system based on polysaccharides for bioactive compounds targeting applications in agriculture. As an example a delivery system for plant growth factors

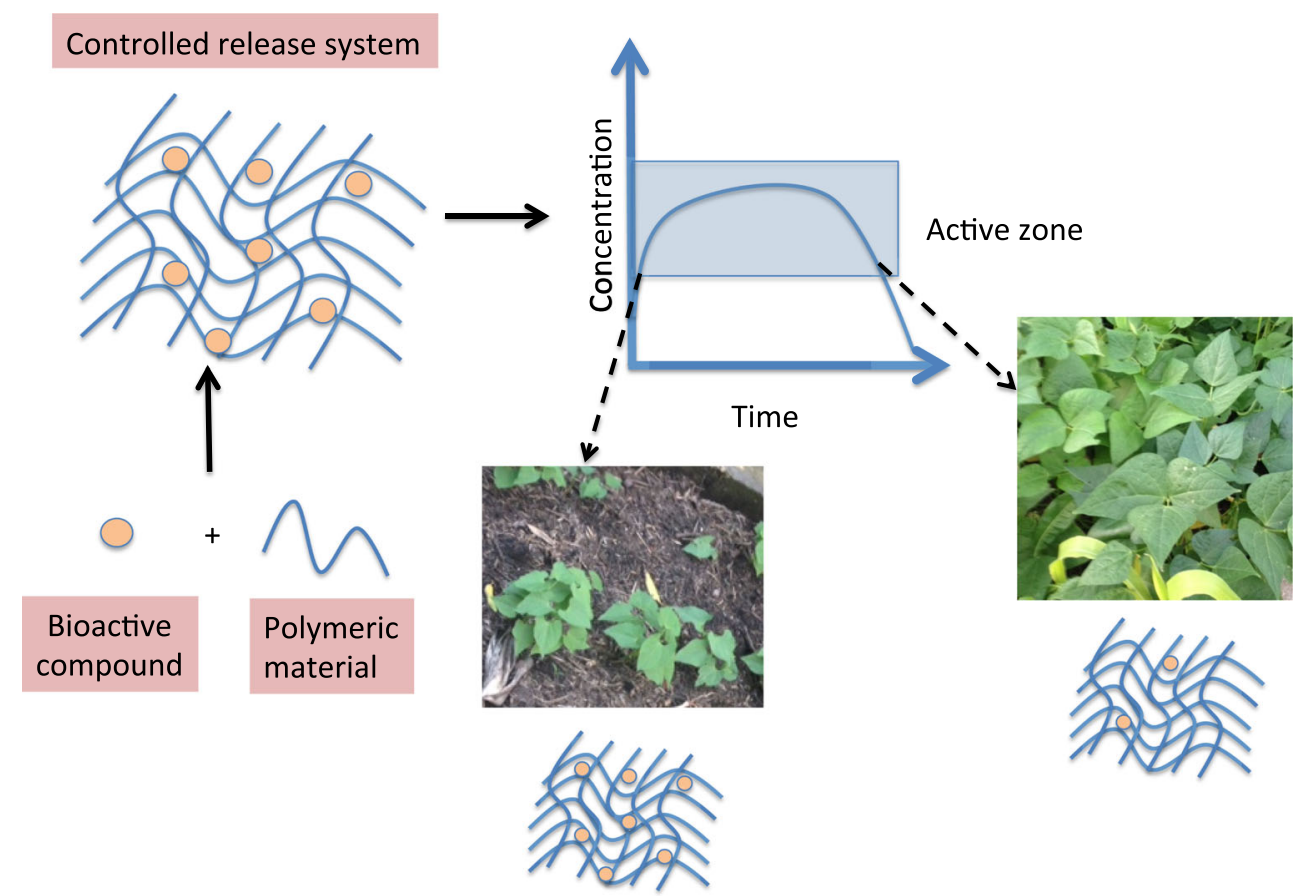


based on natural polymers formed by physical combination have attracted considerable attention as an excellent candidate for development of controlled-release pesticide formulations.

\section{Commonly used biopolymers for agrochemical delivery systems}

Polysaccharides are macromolecules composed of monosaccharide units linked by glycosidic bonds (Liu et al. 2008; Raemdonck et al. 2013). These compounds are found widely in nature, including in algae (alginate), plants (cellulose, pectin, cyclodextrin, and starch), microorganisms (dextran), and animals (chitosan) (Liu et al. 2008; Raemdonck et al. 2013). The molecules can be linear (for example, chitosan) or cyclic (such as cyclodextrin), and differ in terms of their charge, which can be neutral, positive, or negative (Hassani et al. 2012). Advantages of these substances include their low cost and ready availability, which facilitates the large-scale production of products derived from them.

One of the applications of polysaccharides is in controlledrelease formulations that are used in a variety of areas, including agriculture. Some of the main polysaccharides employed as carriers in agriculture are described below.

\subsection{Alginate}

Alginate (Fig. 3), obtained from brown macroalgae, is a linear polysaccharide composed of 1-4 bonds of $\beta$-D-manuronic acid $(\mathrm{M})$ and $\alpha$-L-guluronic acid $(\mathrm{G})$, with variations in the composition and sequential structure along the chain (Zhang and Zhao 2007; Lertsutthiwong et al. 2008). The polysaccharide can be used for the sustained release of agrochemicals after passing through an ionotropic gellification process employing metal ions (Fernández-Pérez 2007; Singh et al. 2013; Wlodarczyk and Siwek 2013).

\subsection{Starch}

Starch (Fig. 3) is one of the main reserve compounds in plants and is abundant in cereal grains, legumes, roots, and fruits. It is a homopolysaccharide consisting of chains of amylose and amylopectin. Amylose is constituted of glucose units connected by $\alpha-(1,4)$ bonds, forming a linear chain, while amylopectin forms branched structures between the glucose units by means of $\alpha-(1,4)$ and $\alpha-(1,6)$ bonds. The relative proportions of these structures vary according to the species from which the starch is obtained, and there can be variations within the same species, depending on the degree of maturity of the plant (Denardin and da Silva 2009; Zhong et al. 2013; Laycock and Halley 2014).

\subsection{Cellulose}

Cellulose (Fig. 3) is the most abundant polysaccharide in nature, and its useful properties include biodegradability, biocompatibility, low toxicity, and low cost. The cellulose molecule is composed of sequences of $\beta$-D-glucopyranose units linked by $\beta-(1,4)$ glycosidic chemical bonds (Beneke et al. 2009). Cellulose and its derivatives are widely used as delivery systems for bioactive compounds, since they are environmentally friendly and can be degraded by many bacteria and fungi present in the air, soil, and water (Raafat et al. 2012; Akar et al. 2012; Hemvichian et al. 2014).

\subsection{Cyclodextrin}

Cyclodextrins (Fig. 3) are complex polysaccharides composed of glucose units ( $\alpha$-D-glucopyranose) connected by $\alpha-(1,4)$ bonds. Enzymatic modification is used to obtain $\alpha$ cyclodextrin (composed of six glucose units), $\beta$-cyclodextrin (seven units), and $\gamma$-cyclodextrin (eight units) (Pérez-Martínez et al. 1999; Pacioni and Veglia 2007). The conical structure, together with the orientation of hydroxyl groups towards the exterior, provides the cyclodextrins with unique physicochemical properties, since they can be solubilized in an aqueous medium, while at the same time they can transport hydrophobic compounds in the interior of their cavities (Britto et al. 2004). Cyclodextrins are widely employed due to their capacity to form inclusion complexes with many molecules (PérezMartínez et al. 1999; De Carvalho and de Alves Pinto 2012; Morin-Crini and Crini 2013; Higueras et al. 2013; Fernandes et al. 2014; Garrido et al. 2014).

\subsection{Dextran}

Dextrans (Fig. 3) are polysaccharides derived from bacteria, composed of glucose monomers connected by $\alpha-(1,6)$ bonds in the main chain and by $\alpha-(1,4), \alpha-(1,3)$, and $\alpha-(1,2)$ bonds in the branches (Ahmed et al. 2012; Raemdonck et al. 2013). The extent of branching, molecular mass, and other properties of dextran vary according to the microorganism employed (Ahmed et al. 2012; De Cicco et al. 2014; Mateen and Hoare 2014).

\subsection{Guar gum}

Guar gum (Fig. 3) is a neutral polysaccharide composed of a main chain of D-mannopyranose residues connected by $\beta-(1,4)$ glycosidic bonds, linked to D-galactopyranose residues by $\alpha-(1,6)$ glycosidic bonds. The solubility of guar gum in cold water increases in line with the galactose/mannose molar ratio (Vaughn et al. 2013; Rutz et al. 2013). 
Fig. 3 Chemical structures of the polysaccharides used to prepare carrier systems for bioactive compounds employed in agriculture

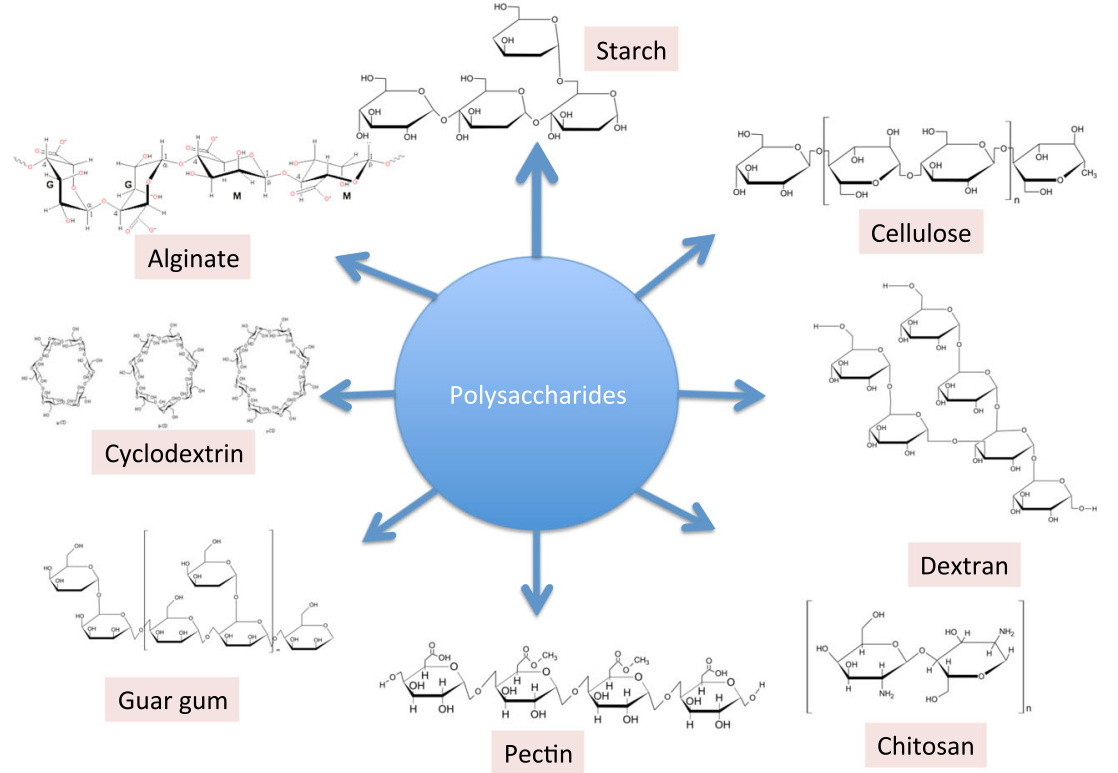

\subsection{Pectin}

The pectins (Fig. 3) are a family of polysaccharides present in the cell walls of higher plants. Their structures consist of Dgalacturonic acid units connected by $\alpha-(1,4)$ bonds, forming a linear polysaccharide interrupted by highly branched regions. The composition of pectin varies according to its botanical source (Lv et al. 2014; Bayarri et al. 2014).

\subsection{Chitosan}

The substance chitin is widely found in nature. It is the main component of the exoskeleton of crustaceans and is found in the cell walls of certain bacteria and fungi. Chitosan (Fig. 3) is a partially deacetylated compound obtained by the deacetylation of chitin in an alkaline medium (Senel and McClure 2004). Chitin is composed of D-glucosamine and $N$-acetyl-D-glucosamine monomers, linked by $\beta-(1,4)$ glycosidic bonds (Senel and McClure 2004; Lertsutthiwong et al. 2008). The extent of deacetylation, the content of impurities, and the distribution of the molar mass of chitosan depends on the natural source of the primary material as well as the preparation method (Senel and McClure 2004; Laranjeira and de Fávere 2009).

Chitosan has acquired widespread appeal for use in many applications in different fields, including in agriculture, since it is non-toxic, biodegradable, and biocompatible. As example, recently, Grillo and coworkers has published the preparation of chitosan/tripolyphosphate nanoparticles as carrier systems to paraquat herbicides. The results showed that these nanoparticles were able to decrease the herbicide toxicity (Grillo et al. 2014).

\section{Polysaccharide-based controlled-release formulation in the form of microspheres and nanoparticles}

A variety of polymeric nano- and microparticles can be used as carriers for bioactive molecules. Depending on the materials and methods used, it is possible to obtain nano- and microspheres, or nano- and microcapsules, which differ both structurally and in terms of their composition. Nanocapsules are systems composed of a polymeric shell and an oily nucleus, where the active principle can be dissolved in the nucleus or adsorbed on the polymeric wall. Nanospheres do not contain oil in their composition, and consist only of a polymeric matrix. In this case, there is no distinct nucleus, and the active principle is adsorbed or retained by the polymeric matrix (Schaffazick et al. 2003; Anton et al. 2008; Mishra et al. 2010).

\subsection{Spheres and microspheres}

Fernández-Pérez et al. (2000) studied the mobility in the soil column of isoproturon released from alginate-bentonite spheres. Simulations were made of typical soil structures, using columns consisting of fractions of sand, peat, altered soil, and native soil. Sorption and desorption tests were performed for all the fractions. It was found that use of the alginate-bentonite formulations resulted in reductions in the vertical mobility of isoproturon, compared to columns containing the herbicide alone. The greatest sorption capacity was obtained for the peat layer. The use of alginate-bentonite could therefore provide an effective system for reducing the amount of herbicide leached through the soil, hence 
diminishing possible risks of contamination of underground water bodies.

Flores Céspedes et al. (2007) described the synthesis of alginate spheres containing different adsorbents (bentonite, anthracite, and activated carbon), and the influence of the adsorbents on the encapsulation efficiency of two herbicides (metribuzin and chloridazon), as well as on the release rates of the active principles in aqueous media. The release rates of systems prepared with metribuzim were faster than those containing chloridazon (which is more hydrophobic than metribuzim). The formulations containing the adsorbents provided slower release of both herbicides, compared to the use of the alginate spheres alone. In terms of reducing the release rate, the most efficient adsorbent was activated carbon.

Guan et al. (2008) prepared, characterized, and evaluated the insecticidal activity of microcapsules of alginate and chitosan used as a carrier system for imidacloprid. Characterization of the particles employed confocal laser microscopy and scanning electron microscopy. Tests investigated the release kinetics and photodegradation of the insecticide, and assays of the insecticidal activity of the systems employed the adult stage of the insect Martianus dermestoide as a model. Evaluation was made of the adsorption of photocatalysts based on silver nitrate $\left(\mathrm{AgNO}_{3}\right)$, titanium dioxide $\left(\mathrm{TiO}_{2}\right)$, and sodium dodecyl sulfate (SDS), and their effect on photodegradation of the insecticide (under visible and UV radiation). The particles obtained were stable and imidacloprid was encapsulated with an efficiency of around $82 \%$. In release assays, it was shown that the release time of the encapsulated insecticide was up to eight times longer, compared to the free insecticide, and that alterations in the concentrations of alginate and chitosan affected the release profile. Tests with the photocatalysts indicated that the formulation utilizing $\mathrm{Ag} / \mathrm{TiO}{ }_{2} / \mathrm{SDS}$ presented the best adsorption characteristics and photocatalytic activity. In terms of insecticidal activity, the toxicity of $50 \%$ microcapsules with imadacloprid and photocatalyst $\left(\mathrm{Ag} / \mathrm{TiO}_{2} / \mathrm{DSS}\right)$ was higher than that of $95 \%$ free imidacloprid, as shown by $\mathrm{LD}_{50}$ values of 13.45 and $9.86 \mathrm{mg} / \mathrm{L}$ for the systems without and with particles, respectively, demonstrating the effectiveness of the particle-based formulation.

Roy and coworkers (2009) investigated the synthesis of microspheres composed of sodium alginate and starch, for use as a carrier system for the insecticide chlorpyrifos. The concentrations of alginate, starch, and reticulation agent $\left(\mathrm{CaCl}_{2}\right)$ were varied, and the effects on the release profile and particle intumescence were evaluated. A higher concentration of alginate and lower concentration of starch favored intumescence, as did higher $\mathrm{pH}$ and temperature. The release rate increased at higher alginate concentrations, but decreased when the content of starch was increased. The best release profile was obtained for microspheres containing more alginate and less starch. Use of the particles effectively controlled the release of the insecticide, since $50 \%$ of free chlorpyrifos was released in only 1 day, while $50 \%$ of the encapsulated insecticide was released in 5 days.

Jerobin et al. (2012) studied the preparation of alginate spheres containing the pesticide azadirachtin, using glutaraldehyde as the reticulation agent and different concentrations of neem oil. Two agents (starch and polyethylene glycol) were used to coat the particles. Both coatings retarded the release of the active principle, compared to uncoated spheres, although starch provided the best modulation of the release profile. The release of azadirachtin increased when higher concentrations of neem oil were used, and the results indicated that variable quantities of the oil could be successfully incorporated in the coated alginate spheres.

Kulkarni et al. (2000) prepared spheres of alginate to carry azadirachtin, using glutaraldehyde as the reticulation agent. The formulations were optimized by varying the time of exposure to the reticulation agent and the percentage loading of neem oil. Different concentrations were successfully encapsulated in the alginate spheres. The particles presented a highly consistent average diameter, with no significant variations according to changes in the concentrations of the components of the spheres, although changes in both variables affected the encapsulation efficiency of the active principle. The release rate was faster for higher concentrations of encapsulated neem oil, while a longer time of exposure to the reticulation agent diminished the release rate. The values of $n$ determined by the release of the neem oil from the spheres were between 0.70 and 0.94 . This result indicates that the release process was governed by Fickian transport.

Sopeña et al. (2007) determined the influence of several variables on the ability of microspheres to reduce leaching of the herbicide alachlor in sandy soils in order to avoid contamination of underground water bodies. The microspheres were able to retard the release rate of the alachlor in relation to commercial formulation. The percentage of herbicide eluted following application of the formulation was around $40 \%$. This percentage was less than expected for a soil with low contents of clay and organic matter (since the interaction of alachlor is influenced by these two soil properties). Changes in the parameters to prepare the microspheres promote changes in the release profile of the herbicide, causing a reduction in leaching, increase the persistence and the concentration in the upper soil layers. The slower release might also assist in the control of weeds over longer periods.

El Bahri and Taverdet (2007) prepared and characterized microspheres loaded with ethyl benzoate as a pesticide model. The microspheres were prepared by a solvent evaporation technique, and double encapsulation was performed using solvent evaporation followed by coacervation. The matrices tested included ethylcellulose, cellulose acetate butyrate, and poly(methyl methacrylate). The microparticles were characterized by scanning electron microscopy (SEM) and Fourier transform infrared spectroscopy (FTIR), and measurements 
were made of the average particle size, together with in vitro release tests and analysis of the parameters involved in synthesis of the microspheres. It was found that use of the cellulose derivatives produced microspheres that were more porous than those obtained using poly(methyl methacrylate), and that the size of the particles was strongly dependent of the polymer matrix, its concentration, and the agitation speed employed during preparation, but less dependent on the emulsifier. Capture of the active principle was strongly dependent on the polymeric matrix, the polymer concentration, and the polymer/active principle ratio. The release of ethyl benzoate could be restricted by using the poly(methyl methacrylate) matrix, increasing the polymer concentration, or by using coated microspheres (microcapsules). The use of cellulose matrices to obtain formulations able to deliver sustained release of agrochemicals was therefore proven viable.

$\mathrm{Wu}$ and Liu (2008) developed and characterized granules of chitosan and poly(acrylic acid-co-acrylamide) for the controlled release of nitrogen, phosphorus, and potassium (NPK), and the retention of water. The granules were characterized by FTIR and atomic absorption spectrophotometry, and tests investigated the in vitro release kinetics and the absorption of water. The granules consisted of three layers: a watersoluble nucleus containing the NPK nutrient mixture, an internal coating of chitosan, and an external coating of absorbent polymer. The granules contained $7.98 \%$ potassium, $8.14 \%$ phosphorus, and $8.06 \%$ nitrogen, and successfully modulated the release of the fertilizer, since less than $75 \%$ of the nutrients had been released after a period of 30 days. Addition of the granules to the soil significantly improved the water retention capacity. The formulation was therefore shown to be a good slow release fertilizer, with the added benefit of being able to assist water retention. It could therefore have potential applications in the remediation of arid regions and areas affected by desertification.

Ni et al. (2009) developed dual-coated particles for the slow release of urea and the retention of water. Ethylcellulose was used for the internal coating, and poly(acrylic acid-coacrylamide) for the external coating. The structural and chemical characteristics of the material were determined using SEM, FTIR, and differential calorimetry (DSC), and evaluation was made of its effectiveness in retarding the release of fertilizer in the soil, as well as its ability to absorb water and its degradability. The particles consisted of three layers: a nucleus containing pure urea, an inner coating of ethylcellulose, and an outer coating of the absorbent copolymer. The nitrogen content was $21.1 \%$, and the particles were able to absorb a quantity of water equivalent to 70 times their own weight. Release kinetics experiments revealed that around $75 \%$ of the active principle had been released after 30 days of incubation with soil. The addition of these particles to soil could therefore significantly improve water retention while providing slow fertilizer release, which would be useful in drought regions, or where water supplies are limited.

Han et al. (2009) described a film based on starch and polyvinyl alcohol (PVA) for the coating of soluble fertilizer granules. Evaluation was made of the influence of the starch/ PVA ratio, permeability to water and ammonium, absorption capacity, and biodegradability in soil. The films were characterized using FTIR, X-ray diffraction (XRD), and atomic force microscopy (AFM). The water absorption, permeability to water, and permeability to ammonium increased in line with the PVA content, while reduced concentrations of starch affected the compatibility of the films. The permeability and absorption capacity of films reticulated with formaldehyde decreased as the formaldehyde concentration increased, due to intramolecular bonding of the hydroxyls of starch and PVA. After 50 days of exposure in the soil, the films became small, fragile, and broken, indicative of their natural biodegradation in the soil environment, and their final weight loss exceeded $50 \%$. The findings showed that starch and PVA could be used to produce films to coat granules of soluble fertilizers, due to their inherent permeability and biodegradability.

Guan et al. (2011) investigated the use of alginate microspheres as carriers of the hormone ecdysone. The microspheres were prepared using internal gelification, and were characterized by confocal scanning laser microscopy (CSLM) and SEM. In vitro release tests were performed, together with evaluation of the stability of ecdysone, either free or encapsulated, during exposure to ultraviolet light. Toxic effects were evaluated using the larvae of $M$. dermestoides Chevrolat. The alginate microspheres showed a high encapsulation efficiency of around $81 \%$, confirming the efficiency of the preparation technique, and an average diameter of $52.8 \pm 9.8 \mu \mathrm{m}$. The concentration of the reticulation agent had a direct effect on the intumescence capacity of the particles. The in vitro release and photodegradation experiments confirmed that the particles were able to modulate the release profile of the hormone, as well as reduce its photodegradation. The toxicity studies showed that the microspheres containing the hormone were more toxic than free ecdysone, as reflected in a lower $\mathrm{EC}_{50}$ value. Finally, the photostability of the microparticles was indicative of a long useful lifetime when used in field applications.

Paula et al. (2010) prepared and characterized microspheres composed of chitosan and cashew tree gum, which were used as carriers of the essential oil of Lippia sidoides, which possesses insecticidal properties. The particles were characterized using SEM, infrared spectroscopy, UV-Vis spectroscopy, thermogravimetric analysis (TGA), and DSC. Evaluation was made of the encapsulation efficiency, intumescence, in vitro release profile, and insecticidal activity against the larvae of Aedes aegypti. The particles showed spherical morphology and were highly porous. The chitosan particles (CT) had an average size of $1.27 \mu \mathrm{m}$ and an essential 
oil encapsulation efficiency of $4.4 \%$, while the corresponding values for chitosan-cashew tree gum particles (CT-CTG) were $1.53 \mu \mathrm{m}$ and $2.4 \%$. The intumescence of CT exceeded that of CT-CTG, and CT required a shorter time to reach equilibrium, while the TGA and DSC analyses demonstrated that the CTCTG particles were more thermally stable than CT. The use of a reticulation agent resulted in a polymeric network that was more rigid, with a low coefficient of diffusion, resulting in release that was more prolonged. In the insecticidal activity assays, both types of particle showed larvicidal activity, with the larvae of $A$. aegypti being successfully eliminated after an exposure period of $72 \mathrm{~h}$. These findings confirmed the suitability of polysaccharides such as chitosan and cashew tree gum for use as matrices to carry bioinsecticides designed to control the proliferation of insect larvae.

Quiñones et al. (2010) described the use of chitosan microspheres to carry synthetic analogues of brassinosteroids and diosgenin derivatives, and tested different ligands in the reactions. The systems were characterized using FTIR and DSC, and release assays were realized in water at different $\mathrm{pH}$ values. The FTIR and DSC results showed that the active principles had been efficiently encapsulated in the chitosan microspheres. When ethanolic solutions of the steroids were used, the encapsulation percentage increased, and in the case of the diosgenins, the best ligand was dicarboxylic acid. The release kinetics assay using water revealed that the least efficiently encapsulated steroids were released fastest from the particles. These results demonstrate that molecular modifications can be used to design effective systems for the delivery and release of agrochemicals.

Sopeña et al. (2011) developed ethylcellulose microspheres for the progressive release of the herbicide norflurazon (NFZ) and compared photodegradation rates with those of a commercial formulation. The microspheres were able to provide a gradual and sustained release of NFZ, as well as substantial protection against photolysis of the herbicide, in both aqueous solution and soil. The slow release acted to reduce the amount of herbicide available for photodegradation. The rate of photodegradation in aqueous solution diminished in the presence of colloidal soil components such as goethite and humic acids, due to their ability to block UV, while this effect was not observed for clay (montmorillonite) and fulvic acids, for which the results were similar to those obtained for the microspheres alone. The use of ethylcellulose in sustained release formulations can therefore reduce the doses of herbicide required, since losses by photolysis are minimized. The effects could be especially advantageous during the first hours following foliar and soil applications, with reductions in losses due to leaching and dissipation.

Flores-Céspedes et al. (2009) studied the preparation and characterization of granules of the herbicide chlorsulfuron coated with ethylcellulose and with addition of a plasticizer (dibutyl sebacate). The effects of the amendments were assessed in terms of the release profile of the active principle, its mobility in a calcareous soil, and the morphology of the granules. Encapsulation efficiency close to $100 \%$ was achieved and the release rate of the active principle could be controlled by adjusting the thickness of the coating agent and modifying its surface by addition of the plasticizer. In soil mobility experiments, it was shown that coating of the granules was able to reduce leaching of the herbicide.

\subsection{Nanoparticles}

dos Silva et al. (2011) studied the release profile and soil sorption of alginate/chitosan nanoparticles used as carriers of the herbicide paraquat. The average size of the particles was $635 \pm 12 \mathrm{~nm}$, and the encapsulation efficiency was $74.2 \%$. Encapsulation of the herbicide in the nanoparticles resulted in a significant change in the release profile of the herbicide, with the release being slower, compared to free paraquat. In soil sorption experiments, it was found that sorption of both the encapsulated and free forms was dependent on the content of organic matter in the soil, although the sorption profile was reduced when paraquat was associated with the nanoparticles, hence improving the herbicidal action.

Geng et al. (2009) developed and characterized nanoparticles of $\mathrm{Fe}^{0}$ stabilized by chitosan $\left(\mathrm{CTO}-\mathrm{Fe}^{0}\right)$, and nanoparticles of $\mathrm{Fe}^{0}$ synthesized in an ethanol-water mixture $\left(\mathrm{EW}-\mathrm{Fe}^{0}\right)$, which were tested for the reduction of $\mathrm{Cr}(\mathrm{VI})$. Characterization was performed using FTIR, XRD, and TEM. They showed that the size average of the particles was $82.4 \mathrm{~nm}$, and that the nitrogen and oxygen atoms were the sites of bonding of chitosan on the iron, and were responsible for the stability of $\mathrm{Fe}^{0}$ in the nanoparticles. The maximum rate of reduction of $\mathrm{Cr}(\mathrm{VI})$ was three times greater for $\mathrm{CTO}-\mathrm{Fe}^{0}$, compared to EW- $-\mathrm{Fe}^{0}$. Because of the protection provided by chitosan, CTO- $\mathrm{Fe}^{0}$ presented good stability in terms of oxidation, and retained a high reduction capacity after exposure to ambient air for 2 months. The combination of fast reaction kinetics and good resistance to oxidation indicates that nanoparticles of $\mathrm{Fe}^{0}$ stabilized with chitosan could be used as an effective agent for environmental remediation.

Lao et al. (2010) produced a new amphiphilic derivative of chitosan, $\mathrm{N}$-(octadecanol-1-glycidyl ether)- $O$-sulfate chitosan, as a carrier for the insecticide rotenone. Characterization was performed using FTIR and nuclear magnetic resonance (NMR), and the critical micellar concentration (CMC) was investigated, together with the release kinetics in water. The FTIR and NMR results confirmed the successful synthesis of NOSCS, and the CMC was between $3.55 \times 10^{-3}$ and $5.50 \times$ $10^{-3} \mathrm{mg} / \mathrm{mL}$. The polymeric micelles formed were spherical, with a size range of between 167 and $204 \mathrm{~nm}$, and the nanoparticles were formed by self-assembly in aqueous solution. The encapsulation of rotenone increased its solubility in 
water 1,300-fold, while in vitro release assays demonstrated that the nanoparticles provided sustained release of the insecticide. The properties of nanomicelles based on NOSCS enable them to be used as carriers to encapsulate and subsequently release insoluble pesticides employed in agriculture.

Wen et al. (2010) studied the bioavailability of the chiral herbicide dichlorprop to the green alga Chlorella pyrenoidosa, in the absence and presence of chitosan nanoparticles. The particles were characterized by FTIR, X-ray spectroscopy, and TEM, and tests of the toxicity and dissipation of the herbicide were performed. The average diameter of the chitosan particles was smaller than $100 \mathrm{~nm}$. In the absence of chitosan, dissipation of the S-enantiomer in a Chlorella vulgaris culture medium was faster than that of the R-enantiomer, while the order of dissipation was reversed when the polysaccharide was used. In the absence of chitosan, the R-enantiomer was more toxic to the algae, while the $\mathrm{S}$ form was more toxic in the presence of chitosan. These observations provided a clear indication that chitosan was able to modify the enantioselective bioavailability of the herbicide, which could be of use in environmental protection applications.

Liu et al. (2011) evaluated the capacity of complexes of polymers and cyclodextrins to adsorb and remove pesticides present in water. Seven different formulations were synthesized using epichlorohydrin as a reticulation agent, and were then characterized using SEM, IR spectroscopy, and DSC. The synthesized particles presented a homogeneous porous spherical morphology. The ability of the particles to adsorb pesticides was confirmed using adsorption kinetics and isotherm assays, in the presence of a mixture of 10 pesticides. The adsorption occurred due to multiple interactions including inclusion in the cyclodextrins, hydrogen bridges, and physical adsorption, among others. Multivariate regression analysis enabled identification of the particle properties that were most significant in terms of adsorption potential: cyclodextrin content, swelling ability, and pore size. A mixture of three types of particles that showed the best adsorption potential was used to determine the removal of the pesticides from water, since this combination was most suitable for the range of pesticide concentrations likely to be found in the environment. The good ability of particles based on polymers and cyclodextrin to adsorb pesticides is indicative of their potential for use in water remediation.

Wen et al. (2011) synthesized and characterized chitosan complexes and nanoparticles of chitosan containing the chiral herbicide dichlorprop, with the aim of reducing the potential for leaching and contamination of subterreanean waters. The complexes were characterized by FTIR, and the inhibition ability of the herbicide was evaluated using two different algae, C. vulgaris and Scenedesmus obliquus. It was found that the sensitivity of the algae varied according to species, with S-dichlorprop being more toxic to Chlorella, while R- dichlorprop was more toxic to Scenedesmus. The use of chitosan nanoparticles resulted in a greater reduction in toxicity to Scenedesmus, compared to plain chitosan, while in the case of Chlorella, the opposite was observed. The chiral selectivity of the herbicide to the two algae was altered when it was complexed with either plain chitosan or the nanoparticles, which could be explained by differences in the physicochemical properties of the two materials, or by differences in the cell walls of the two algae.

Celis et al. (2012) used different methods to prepare a bionanocomposite material based on chitosan and clay (montmorillonite), used as an adsorbent for the herbicide clopyralid present in an aqueous solution or in a mixture of water and soil. The nanoparticles were characterized using FTIR, X-ray spectroscopy, and SEM. The bionanocomposites showed good herbicide adsorption capacity at $\mathrm{pH}$ levels at which the anionic form of the active principle and the cationic form of chitosan predominated. Removal of the herbicide from aqueous solution was more effective when a higher concentration of chitosan was used in the bionanocomposite. At slightly acid $\mathrm{pH}$, the composites effectively adsorbed clopyralid from soil. The use of this type of formulation could help to limit the mobility of anionic pesticides in the environment, reducing risks of contamination of surface and subterranean water bodies.

Feng and Peng (2012) synthesized a new compound based on chitosan, using carboxymethyl chitosan (CM-C) with ricinoleic acid (RA). Investigations were made of the reaction conditions required for its formation, and the products were characterized with the aim of producing a formulation suitable for use as a carrier of the biopesticide azadirachtin (AZA). The concentrations of the components were varied, and the stability of the resulting formulations was determined by measurements of particle size, polydispersion, and zeta potential. The particles were analyzed using IR spectroscopy and SEM, and the release of AZA was measured in an aqueous medium. Under suitable conditions, the liposoluble group of RA reacted with the hydrosoluble group of $\mathrm{CM}-\mathrm{C}$, producing the amphiphilic compound RA-CM-C, a micellar polymer that is self-assembling in water. The concentrations of the components influenced the stability of the formulations. The particles presented good polydispersion, with a size range of 200 $500 \mathrm{~nm}$, as well as smooth spherical morphology and high zeta potential. The AZA encapsulation efficiency was $56 \%$, and the particles were able to release the pesticide over a period of 11 days. The use of the carrier assisted the solubilization in water of this lipid-soluble pesticide, and could therefore offer advantages in agricultural applications.

Tao et al. (2012) synthesized chitosan modified with 1naphthylacetic acid, which is an important plant growth hormone. The material was characterized using FTIR, thermogravimetric analysis, and NMR. In the modified chitosan, the main polysaccharide chain contained both amino and 
naphthylacetyl groups. The release of the 1-naphthylacetic acid was strongly dependent on $\mathrm{pH}$ and temperature, and could continue for 55 days at $\mathrm{pH} 12$ and $60{ }^{\circ} \mathrm{C}$. Despite this dependence, the formulation offers potential for the slow release of agrochemicals such as hormones.

Zhong and coworkers (2013) developed a superabsorbent polymer based on sulfonated maize starch (SMS) and poly (acrylic acid) (PAA) for the incorporation of rock phosphate (RP). The complexes formed were characterized using XRD and FTIR, and in vitro release assays and water absorption experiments were performed. It was found that RP could be satisfactorily dispersed in the SMS-PAA medium, and that the water absorption capacity was influenced by the relative ratios of the different components (SMS, PAA, and RP). The system was able to provide a sustained release of phosphate, as well as excellent water retention, making it potentially valuable for use in crop production.

Table 1 provides a summary of the main polysaccharides used in the studies described above, together with the types of carrier systems and active principles.

\section{Polysaccharide-based controlled-release formulation in the form of beads and polymeric networks/hydrogels}

Hydrogels are hydrophilic polymeric networks that are able to retain large quantities of water without losing their threedimensional structure (in other words, without dissolving). Cross-bonding between the polymeric chains forms the tridimensional structure, and the network can be built in different ways, by means of covalent bonds, hydrogen bridges, van der Waals forces, or physical interactions (Yoshida et al. 1993; Andrianov and Payne 1998; Qiu and Park 2012). Hydrogels are prepared by using natural/synthetic polymers. Those obtained from natural polymers possess mechanical properties that cannot be controlled, due to the inherent variability. On the other hand, hydrogels derived from synthetic polymers have consistent defined properties, although most of these substances are not biodegradable (Hoffman 2012). There is currently a move towards the use of "intelligent" hydrogels that are able to respond to environmental stimuli (such as light, $\mathrm{pH}$, temperature, or the presence of specific molecules), resulting in structural changes in the hydrogel and the concomitant release of the active agent (Soppimath et al. 2001; Qiu and Park 2001).

Alginate is a water-soluble linear polysaccharide can be used to prepare the agrochemical loaded beads formulation through ionotropic gelation (Ertesvåg and Valla 1998; Mørch et al. 2006). Alginate beads are prepared by dropping a solution of sodium alginate containing the desired active ingredient in the form of droplets, into a metal ion solution which acts as crosslinker. These have been used as controlled-release formulations of pesticides after ionotropic gelation with metal ions (Ișiklan 2007). Although the ionotropic gelation of alginate with metal ion is a simple and fast way of obtaining bead formulations but it is associated with a limitation which is loss of active ingredient during bead preparation (Ferreira Almeida and Almeida 2004; George and Abraham 2006). One way to circumvent this limitation is to prepare bi-polymeric bead formulation by using some other natural polysaccharide along with alginate. It is worth to mention here that alginate in soil undergoes enzymatic or radiolytic degradation to produce plant growth promoter oligo-alginates which were found to elicit germination, shoot elongation, and root growth promoting activity (Abd El-Rehim 2006). The presence of alginate in pesticide formulations also helps in crop growth. Various clays have been used as the modifiers or additives in polymer-based controlled-release systems to further control the release profile the pesticides (Flores-Céspedes et al. 2009; Bergaya and Lagaly 2013). Flores Céspedes et al. (2013) have used bentonite as modifying sorbents in alginate-based controlled-release formulations. They have observed the decrease the rate of release of active compound as compared to the market product. Apart from controlling the release rate, the incorporation of bentonite in alginate has also been found to increase the granule yields, therefore results in more efficient and cheaper formulation (Bergaya and Lagaly 2013). The clay also helps in retaining nutrient ions and thus make soil as a useful medium for the growth of plants due its ion exchange nature (Dixon 1991).

Alginates-based controlled-release formulations have been investigated with various herbicides such as monolinuron, desmetryn, chloridazon, atrazine, simazine, and chloroxuron as active ingredients. Release rate from these formulations showed sufficient retardation of herbicide release (Pfister et al. 1986). Pepperman and Kuan (1993) have observed the alginate formulations have decreased the rate of release of metribuzin herbicide compared to the conventional formulation. In another study, the release rate of isoproturon herbicide from the alginate formulation also decreased as compared to the technical product (Villafranca-Sánchez et al. 2000). The use of controlled-release systems has also reduced the vertical mobility of herbicide into the soil (Fernández-Pérez et al. 2000). Further, the utility of these systems can be improved by combining more than one herbicides or combining herbicide and fertilizer in a single formulation (Johnson and Pepperman 1998). The application of pesticide mixture in agriculture is also desirable to provide effective pest control and to counter the development of resistance in the pathogens (Birch and Shaw 1997). After comparing, release rates and mechanisms of herbicides from simple conventional formulations completely finished within single day, whereas release from alginate based on controlled-release systems lasted up to 2 weeks. Hence, it is possible to control the rate of pesticide release by suitably modifying and adjusting the experimental 
Table 1 Summary of polymers, carrier systems, and bioactive compounds with applications in agriculture

\begin{tabular}{|c|c|c|c|}
\hline Carrier/polysaccharide & Active principle & Class & Reference \\
\hline Alginate-chitosan spheres & Imidacloprid & Insecticide & Guan et al. (2008) \\
\hline Starch-alginate spheres & Thiram & Fungicide & Singh et al. (2009a, b, c) \\
\hline Alginate microspheres & Ecdysone & Hormone & Guan et al. (2011) \\
\hline Starch-alginate microspheres & Chlorpyrifos & Insecticide & Roy et al. (2009) \\
\hline Alginate-starch-clay spheres & Thiram & Fungicide & Singh et al. (2009a, b, c) \\
\hline Agar/alginate beads & Thiram & Fungicide & Singh et al. (2009a, b, c) \\
\hline Alginate particles & Carbofuran & Insecticide/nematicide & Fernández-Pérez et al. (2000) \\
\hline Alginate granules & Chloridazon and metribuzin & Herbicides & Flores Céspedes et al. (2007) \\
\hline Alginate spheres & Azadirachtin & Biopesticide & Kulkarni et al. (2000) \\
\hline Alginate nanoemulsion & Azadirachtin & Biopesticide & Jerobin et al. (2012) \\
\hline Alginate hydrogel & Clomazone & Herbicide & Wlodarczyk and Siwek (2013) \\
\hline Alginate-chitosan nanoparticles & Paraquat & Herbicide & dos Silva et al. (2011) \\
\hline Cellulose films & - & - & Qiu et al. (2012) \\
\hline $\begin{array}{l}\text { Microspheres of ethylcellulose, cellulose acetate, } \\
\text { butyryl butyrate, and poly(methyl methacrylate) }\end{array}$ & Ethyl benzoate & Model pesticide & El Bahri and Taverdet (2007) \\
\hline Ethylcellulose & Urea & Fertilizer & Ni et al. (2009) \\
\hline Carboxymethylcellulose hydrogel & - & - & Akar et al. (2012) \\
\hline Ethylcellulose microparticles & Norflurazon & Herbicide & Sopeña et al. (2011) \\
\hline Ethylcellulose & Alachlor & Herbicide & Sopeña et al. (2007) \\
\hline Ethylcellulose & Chlorsulfuron & Herbicide & Flores-Céspedes et al. (2009) \\
\hline Chitosan nanoparticles and chitosan & Dichlorprop & Herbicide & Wen et al. (2011) \\
\hline Chitosan & Dichlorprop & Herbicide & Wen et al. (2010) \\
\hline Montmorillonite-chitosan bionanocomposites & Clopyralid & Herbicide & Celis et al. (2012) \\
\hline Chitosan nanoparticles & Hexavalent chromium & Metal & Geng et al. (2009) \\
\hline Chitosan & - & - & Alves and Mano (2008) \\
\hline Chitosan & NPK & Fertilizer & Wu and Liu (2008) \\
\hline Chitosan & - & - & El-Sawy et al. (2010) \\
\hline Chitosan microspheres & Brassinosteroids & Hormones & Quiñones et al. (2010) \\
\hline Chitosan & Rotenone & Insecticide & Lao et al. (2010) \\
\hline Chitosan & 1-Naphthylacetic acid & Hormone & Tao et al. (2012) \\
\hline Starch-PVA film & - & - & Han et al. (2009) \\
\hline Cyclodextrins & Bendiocarb and promecarb & Insecticides & Pacioni and Veglia (2007) \\
\hline Chitosan/ $\beta$-cyclodextrins Films & Carvacrol & Insecticides & Higueras et al. (2014) \\
\hline Hydroxypropyl- $\beta$-cyclodextrin & Pyrimethanil & Fungicide & Fernandes et al. (2014) \\
\hline$\beta$-Cyclodextrin & MCPA & Herbicide & Garrido et al. (2014) \\
\hline$\beta$-Cyclodextrin & $(2,4-D)$ & Herbicide & Pérez-Martínez et al. (1999) \\
\hline$\beta$-Cyclodextrin & Chlorpropham & Herbicide & Ge et al. (2011) \\
\hline Maize starch & Phosphate & Nutrient & Zhong et al. (2013) \\
\hline
\end{tabular}

protocol. The reaction parameters for the synthesis of beads such as concentrations of crosslinker, pesticide, alginate to gelatin ratio, and temperature affect the release profiles of pesticide from the controlled-release systems (Roy et al. 2009).

The presence of the crosslinker in the formulations affects release of active compound from the formulations. In one study, it has been observed that carbaryl insecticide release from $\mathrm{Ni}$-alginate beads was faster than that of $\mathrm{Ca}$-alginate beads (Ișiklan 2007). In another study, it has been shown slower release of carbaryl from barium crosslinked alginate as compared to $\mathrm{Cu}$-alginate beads. Bajpai and Sharma (2004) have found that under alkaline conditions the bariumcrosslinked beads exhibited minimum swelling but possessed 
greater stability in comparison to beads crosslinked with calcium ions. The addition of additives also changes the release rate of pesticides from the release systems (Pepperman and Kuan 1993, 1995; Fernández-Pérez et al. 2000, 2001; Fernández-Pérez 2007). Addition of the starch into the alginate bead formulations has improved the size, shape, and swelling of the alginate beads (Kim et al. 2005).

Recently, Singh and coworkers (Singh et al. 2008, 2009a, b, c, 2010a, b, 2013) have prepared the polysaccharide-based pesticide delivery formulations based on, alginate, agar, starch, and neem leaf powder. These beads were prepared with ionotropic gelation of these polysaccharides with metal ions $\left(\mathrm{Ca}^{+2}, \mathrm{Ba}^{+2}\right.$ and $\left.\mathrm{Al}^{+3}\right)$ solution. The release of fungicide from the alginate beads containing starch decreased with increase in starch content. This was due to formation of compact polymeric networks in the beads which not only restrained the mobility of polymeric chains, but also brought about shrinkage in the matrix pores. The similar observation has been observed by Roy et al. (2009) where the increase in content of gelatin in alginate-gelatin beads decreased the release of cypermethrin insecticide from the formulations. Similar results have also been observed by other workers (Kulkarni et al. 2000). It is well-known that starch and alginate degrade in the soil. Both, swelling and degradation, of the alginate and starch-based formulation were responsible for the release of pesticide. In soil, various other factors control the release profile of the chemicals from the beads formulations. The enzymes, amylase/alginate lyases, catalyze the degradation of polymer matrix formed from starch and alginate (Trimnell et al. 1985; Wong et al. 2000).

Hydrogels specially based on natural polymers have been used as controlled-release devices for the encapsulation of pesticides (Kenawy 1998; Rudzinski et al. 2002; Puoci et al. 2008). Nowadays, natural polymers-based superabsorbent hydrogels have been observed material of great interest in the scientific and industrial field due to their biodegradable character and the high swelling capacity (Esposito et al. 1996; Sannino et al. 2003).

Hydrogels are crosslinked polymeric networks which swell quickly by imbibing a large amount of water. Hydrogel-based agrochemical delivery system binds the soil and increase the water retaining capacity besides providing the slow release profile to the pesticide. Water retention in the agriculture promotes an increase in germination of seeds in the soil. It also reduces water and nutrient losses during the crop cycle. It will further diminish the irrigation cost and overall crop management costs. In one study, addition of $2 \mathrm{~g}$ hydrogel $/ \mathrm{kg}$ coarse sand has increased the water retention capacity from 171 to 402 \% (Johnson 1984; Woodhouse and Johnson 1991). Beside, water-holding capacity, hydrogels also improve the physical properties of soil by enhancing soil permeability and infiltration rates, reducing irrigation frequency, reducing compaction tendency, stopping erosion and water runoff, increasing plant performance, increasing soil aeration, delaying dissolution of fertilizers (improving fertilizer retention in soil), increasing sorption capacity or favoring the uptake of some nutrient elements by the plants and increasing microbial activity. All these properties, directly or indirectly, are beneficial to plants (Fonteno and Bilderback 1993; Bouranis et al. 1995; Ben-Hur and Keren 1997; Sojka et al. 1998; Akhter et al. 2004).

The decomposition of organic polymeric products in soil by microbial activities promote soil aggregate stability by gluing particles together within aggregates, as well as coating aggregate surfaces (Yangyuoru et al. 2006). Poly(acrylamide) [poly(AAm)] which can be used for grafting,has been reported as an anti-erosion additive, used in irrigation water to control soil erosion associated with flood furrow and sprinkler irrigation (Lentz and Sojka 1994). It has also been observed that addition of acrylamide-based hydrogels has increased the enzymatic activity of soil amidase besides increasing the bacterial growth and concentration of $\mathrm{NO}_{3}{ }^{-}$and $\mathrm{NH}_{4}{ }^{+}$ions in the soil (Kay-Shoemake et al. 1998, 2000). The activity of controlled-release systems can further be enhanced if these are made up of the material which after degradation acts as fertilizer. The use of urea-formaldehyde in controlled pesticide release formulations is an example where in addition to controlling the rate of release of pesticide, the release formulation also acts as fertilizer in a normal manner during its degradation (Akelah 1996; Kumbar et al. 2001; Kulkarni et al. 2002).

Various natural polymers have been used to develop the hydrogels. Starch-based hydrogels are most commonly used hydrogels meant for agrochemical delivery system (Baur 1980; Schreiber et al. 1988; Jana et al. 2001; Frederiksen et al. 2002). In the field, soil moisture, soil microorganisms, and soil enzymes (such as amylases) control the release of the active compounds from polymer matrices (Shasha et al. 1981; Wing and Otey 1983; Trimnell et al. 1985). Grafting is an efficient approach to achieve biopolymer-based hydrogels (Sadeghi and Hosseinzadeh 2008). Carboxymethylcellulose(CMC) and acrylamide-based hydrogels have been prepared by chemical and radiation methods and have been used as release systems of agrochemicals (Bajpai and Giri 2003; Abd El-Mohdy 2007). The release rate of potassium nitrate entrapped within the $\mathrm{CMC} /$ poly(AAm) matrix increased by enhancing its loading percentage, and decreased with lowering AAm content and irradiation dose. The percent loading and chemical composition of the polymer matrix also affect the release rate and released amounts of AI (Bajpai and Giri 2002). The release of paraquat from methylcellulose-poly(AAm) hydrogels has been observed faster in the initial stages than the latter stages and release occurred in several days in controlled manner. It has also been observed that pesticide level in the field was maintained constant from 2 to 7 weeks (Aouada et al. 2010). Zhu and workers have developed release systems of insecticide 
by complex coacervation process using gelatin and acacia gum (Zhu et al. 2009).

Controlled-release systems of metribuzin based on polyvinyl chloride, CMC, and CMC-kaolinite composites have provided a better control which is about $75 \%$ of weeds in comparison to commercial formulation of metribuzin $(57.14 \%)$ after 90 days of wheat sowing. It has also been observed that negligible metribuzin residue left in soil after wheat harvesting and this residue was within prescribed limit of EPA (Kumar et al. 2010). The release of atrazine from polymeric matrix occurred by diffusion of AI through the matrix (Grillo et al. 2012).

The release of herbicides from the carrier system is affected by the formulation parameters (Sopeña et al. 2005, 2007). Fernandez-Urrusuno et al. (2000) have developed the microspheres of alachlor by the solvent evaporation technique using ethyl cellulose as pre-existing polymer. Villafranca-Sanchez et al. have observed that isoproturon herbicide containing controlled-release systems has maintained much slower release in soil column as compared to the in vitro release in water due to (1) occlusion and (2) slower rate of diffusion.

Singh et al. $(2007,2008)$ have reported the thiram containing hydrogels based on starch-AAm/MAAm/MAAc for the slow release of thiram by free radical graft copolymerization method. These workers have observed that these polymeric matrices (hydrogels/beads) have good water-holding capacity. Hence, this property can further be exploited for water management during agricultural activities (Fonteno and Bilderback 1993; Bouranis et al. 1995; Ben-Hur and Keren 1997; Sojka et al. 1998; Akhter et al. 2004). Bajpai and Giri (2003)have observed the decrease in release rate and release amount of $\mathrm{KNO}_{3}$ with increase in crosslinker concentrations in (CMC-g-poly(AAm) hydrogels. Shukla et al. (1991) have also observed the similar observation for the release of pesticide from the pesticide loaded polymeric matrix based on starch. Mobility experiments have shown that the use of alginate-based on release system containing chloridazon has reduced the presence of herbicides in the leachate compared to technical products, mainly for chloridazon (Flores Céspedes et al. 2013). Niu and Li (2012) have prepared the urea encapsulated starch-g-poly(vinylacetate) formulation and results showed that the urea encapsulation efficiency increased with the graft efficiency of poly(vinylacetate). The St-g-PVAc exhibited relatively low swellability, large encapsulating capacity, and a slow-release rate. Otey et al. (1984) have prepared the starch matrix for controlled release of urea fertilizer.

Biodegradable hydrogels have received much attention from the agricultural sector in recent years, such as: controlled-extended release of agricultural inputs, soil conditioners, and erosion control. The use of conditioners has contributed to increase the water retention capacity in the soil, reducing the irrigation frequency, minimizing costs, and helping to improve the yield in cultures. Due to the direct influence of swelling on the release found for these polymer matrices. The adjustment of the swelling behavior by formulating mixtures with other polymers proves to be an interesting tactic to modify the release of the fertilizer (Roy et al. 2014; Zhang et al. 2014a). In case of fertilizer chemicals, hydrogels are capable of storing large amounts of fertilizer, gradually releasing it into the soil, retaining the fertilizers concentration longer and in optimal conditions. This avoids unnecessary expenses and minimizes the environmental impacts caused by overuse of fertilizers in the plantations. The applicability of poly(acrylamide) and methylcellulose (PAAm-MC) hydrogels as potential delivery vehicle for the controlled-extended release of ammonium sulfate $\left(\mathrm{NH}_{4}\right)_{2} \mathrm{SO}_{4}$ and potassium phosphate $\left(\mathrm{KH}_{2} \mathrm{PO}_{4}\right)$ fertilizers have been reported by Bortolin et al. (2012). The addition of $\mathrm{MC}$ in the PAAm chains increased the quantities of $\left(\mathrm{NH}_{4}\right)_{2} \mathrm{SO}_{4}$ and $\mathrm{KH}_{2} \mathrm{PO}_{4}$ loaded and extended the time and quantities of fertilizers released. Coherently, both loading and releasing processes were strongly influenced by hydrophilic properties of hydrogels (AAm/MC mass proportion). The process of releasing fertilizer was prolonged to $8 \mathrm{~h}$ in water from the Slow-release fertilizer encapsulated by graphene oxide films (Zhang et al. 2014a). The development of controlled-release coated urea (CRCU) not only reduces nitrogen loss caused by volatilization and leaching, but also alters the kinetics of nitrogen release, which, in turn, provides nutrients to plants at a pace that is more compatible with their metabolic needs (Azeem et al. 2014). It should also be noted that for uses in agriculture, biocompatible matrices are preferred in order to avoid environmental pollution. Carrageenan is a naturally occurring anionic sulfated linear polysaccharides extracted from certain red seaweed. Carrageenan gel and immobilized microbial cells method was used for 4-chlorophenol degradation (Prajapati et al. 2014).

Chowdhury (2014) has reported a range of bioactive materials aimed for agricultural utilisations, viz., herbicides, pesticides, insecticides, and fertilizers for their controlled release studies, which have been formulated either with lignin or lignin-based biopolymers. Due to the presence of various functionalities in bioactive materials, and their interactions with the functional groups that are present in the lignin structure, were evident and, it affected the water diffusion and bioactive release behavior. The size of the slow release formulated lignin granules impacted on the bioactive release behavior. Smaller-sized granules showed an increased bioactive release while in the larger-sized granules the bioactive release has been decreased. Emulsion cross-linking of alginate with calcium ions produces calcium alginate nonoparticles gels that function as water reservoirs and, therefore, may prove to be an excellent means to provide sustained irrigation in areas where water is scarce. The slow watering potential of composites was also demonstrated with soil-pot experiments, in which plants exhibited much better growth when nanoparticle-mixed soil was used (Sharma et al. 2014). 
Rashidzadeh et al. (2014) have found that the presence of the clinoptilolite zeolite in the Sodium alginate-g-Poly (acrylic acid-co-acrylamide)/Clinoptilolite hydrogel caused the system to liberate the nutrient in a more controlled manner than that with the neat hydrogel. The prepared hydrogel nanocomposite formulation releases about $54.23 \%$ of fertilizer in 30 days which is an indication of a good slow-release property. Consequently, the good slow-release fertilizer property as well as the good water adsorption capacity showed that this formulation is potentially viable to be used in agriculture as a nutrient carrier vehicle. The investigation of the fertilizer release mechanism from hydrogel composite indicated that in this system the fertilizer nutrients release followed a Fickian diffusion type transport mechanism. Similar water-retaining and controlled-release fertilizers formulations have been reported in case of starch-based (Zhong et al. 2013) and methyl cellulose-based (Bortolin et al. 2013) formulations. Super absorbent polymer (SAP) in three levels, 0.15, 0.3, and $0.45 \%$ have been mixed with sandy loam soil. This study was aimed to evaluate the saturated water content, evaporation rate and water-holding capability of SAP treated soils, determine seed germination rate and plant survivals in soil with SAP by absorbing and spraying experiments. The addition of SAP to the sandy loam soil resulted in a significant increase of the soil water retention compared to the controls. Also, the seed germination was significantly higher in SAP amended soil than in the soil without SAP, survival times of grass and woody were prolonged under water stress. $0.30 \%$ SAP treatment was the optimum selection for sandy loam soil improvement on steep rocky slopes. These studies indicated that SAP with good water retention properties was very effective in enhancing water uptake and utilization of water for plants growth and could be expected to have wide potential applications in rocky slopes (Yang et al. 2014).

The most common mechanism of solute release in superabsorbent system is diffusion. The release of solute from loaded superabsorbent involves the absorption of water into the matrix and simultaneous release of solute by diffusion. Highly swelling hydrogel releases a greater amount of solute entrapped within the hydrogels. The primary factor for the application of hydrogels as the carrier of agrochemical is the effect of percent loading on the release of agrochemical.

Hemvichian et al. (2014) have prepared superabsorbent polymer by radiation-induced grafting of acrylamide onto carboxymethylcellulose in the presence of a crosslinking agent. It has been found during the release study that the loading percentage of hydrogels increased with increasing concentration of $\mathrm{KNO}_{3}$. This is due to the fact that $\mathrm{KNO}_{3}$ diffusion increased inside the hydrogeles, thus the amounts of $\mathrm{KNO}_{3}$ released increases with increasing loading percentage of hydrogels. Higher loading leads to faster movement of solvent penetrating the surface of the loaded hydrogels .
Slow-released NPK fertilizer encapsulated by superabsorbent composite has been prepared via in situ free radical polymerization of sodium alginate, acrylic acid, acrylamide, and montmorillonite in the presence of fertilizer compounds by Rashidzadeh et al. (2014). Results indicated that the presence of the montmorillonite caused the system to liberate the nutrient in a more controlled manner than that with the neat superabsorbent. Hence, use of hydrogels in formulation of slow-release fertilizers has attracted a lot of attention due to the increase of the fertilizer use efficiency and preventing environment pollution. The overall results eventually suggested that the hydrogels not only has a slow-release property but also has good water adsorption capacity, which can reduce loss of fertilizer and improve the utilization of water in agricultural applications.

\section{Cyclodextrins as carrier system to agrochemicals}

The cyclodextrins, products of the bacterial degradation of starch, are cyclic polysaccharides consisting of at least six glucose units interconnected by glycosidic bonds. The $\alpha, \beta$, and $\gamma$ cyclodextrins contain six, seven, and eight glucose units, respectively (Britto et al. 2004). Their structure takes the form of a truncated cone, containing a hydrophobic cavity in its interior and $\mathrm{OH}$ groups directed towards the exterior, resulting in a polar surface. This conformation enables cyclodextrins to dissolve hydrophobic compounds in an aqueous medium (Terada et al. 1997; Britto et al. 2004).

Ge et al. (2011) investigated the production of an inclusion complex between the herbicide chlorpropham and $\beta$-cyclodextrin. The characteristic features of this material included the presence of hydrophobic interactions and hydrogen bonds. The complexation involved two molecules of $\beta$-cyclodextrin to every molecule of the herbicide, with one of the $\beta$ cyclodextrin molecules incorporating the isopropyl radical, and the other interacting with the chlorophenyl radical. The complexation resulted in significant improvement of the solubility and thermal stability of the herbicide.

Pérez-Martínez et al. (1999) evaluated the effect of the presence of $\beta$-cyclodextrin on the sorption and desorption of 2,4-D in the soil. The adsorption capacity was greater for soils that had been previously treated with 2,4-D and at the same time with $\beta-\mathrm{CD}$, compared to untreated soil. In sorption/ desorption experiments, it was shown that the removal of $2,4-\mathrm{D}$ was improved in the presence of $\beta-\mathrm{CD}$.

Akar et al. (2012) synthesized a biodegradable hydrogel using fumaric acid (FA) and sodium carboxymethyl cellulose (SCC), for possible use in formulations for the sustained release of agrochemicals. The hydrogels were characterized using FTIR, SEM, XRD, TGA, exploratory DSC, and AFM. The sensitivity to $\mathrm{pH}$ was determined, as well as the biodegradability of the hydrogels. The results showed that an ester 
bond was formed due to the reticulation between the carboxymethyl cellulose and fumaric acid. The roughness of the gel decreased when the concentration of the reticulation agent was increased, and hydrogels produced using lower concentrations of fumaric acid showed greater intumescence capacity. Ionic strength had a clear effect on the intumescence capacity, and the biodegradation of hydrogels produced with higher proportions of FA was slower, with a half-life of $21 \mathrm{~h}$. The work suggested that hydrogels based on SCC/FA were suitable for applications involving the sustained release of agrochemicals, due to their selectivity and degradability.

Fernandes et al. (2014) prepared an inclusion complex of pyrimethanil (fungicide) with hydroxypropyl- $\beta$-cyclodextrin (HP- $\beta-C D)$ and characterized by nuclear magnetic resonance spectroscopy. The results showed that the inclusion complex increased the solubility of pyrimethanil in water around five times when compared with fungicide solubility in water. The formation of pyrimethanil/HP- $\beta$-CD inclusion complex increased significantly the photostability of this fungicide in aqueous solutions (in special in river water). The results founded in this paper showed that the inclusion complex of the fungicide with CDs may the fungicide effectiveness for future applications.

Garrido et al. (2014) investigated the microencapsulation of 4-chloro-2-methylphenoxyacetic acid (MCPA) herbicide in beta-CD and methyl and hydroxypropyl derivatives. The complexes were characterized by phase solubility studies, nuclear magnetic resonance (NMR), and molecular modeling studies. The phase solubility studies showed that $\beta-\mathrm{CD}$ and their derivatives increased the water solubility of the herbicide and the complex stoichiometric is 1:1 (herbicide/cyclodextrin). NMR studies showed that the phenyl moiety of the herbicide was included in the cyclodextrins cavities. Molecular modeling studies indicated that functionalized $\beta$-CDs showed an increase in the binding affinity of MCPA in relation to $\beta$-CD. These results can be important in order to use these systems as release systems in agricultural.

\section{Prospects}

As demonstrated throughout this review, the polysaccharides have been widely used in research in order to develop new formulations with active compounds of interest in agriculture. However, despite the large number of studies in the area, there are no reports of release formulations containing polysaccharides as delivery systems for agriculture, making the topic very promising for the study. Among the advantages of using polysaccharides in developing these formulations are: its availability, being found in large amounts in various different kinds of matrices in nature; the costs associated with these compounds are low, which makes possible the large scale production of products, and the wide range kind of polysaccharides that can interact with many hydrophobic/ hydrophilic compounds. Despite these advantages, many challenges are still needed for use in commercial formulations of polysaccharides, for example, the process of scheduling the formulations-based polysaccharides.

Another area that has been highlighted within this topic and one of the most prominent areas for the use of polysaccharides as delivery systems for agricuture is its association with nanotechnology. The release systems based on nanostructured polysaccharides may offer advantages in terms of release profile of the active, minimizing the environmental impacts and increasing the efficacy of the biological active compound (Grillo et al. 2014). The use of nanotechnology may also, through functionalization of nanoparticles lead to targeted delivery of active ingredient to its target, as well as the association of nanoparticles based on polysaccharides with inorganic nanoparticles (such as magnetic example) can be used to release through processes magnetic hyperthermia, causing the release of an bioactive compound to a target.

Also in relation to the release of active targeting and nanotechnology applications in agriculture, we highlight the development of carrier-based systems in association with botanical insecticides. This development has brought many benefits, in particular reducing the impacts to the environment caused by the use of pesticides to pest control.

However, even with advances in nanotechnology towards polymeric delivery systems assets, it is important to evaluate the aspects of safety and toxicity of these systems before their use in agriculture.

\section{Conclusions}

It is concluded from the forgone discussion that increase in agricultural productivity is required to meet the growing demand of agri-produce. It could be increased by the use of fertilizers and pesticides. However, there is currently great concern about the damage caused to the environment by these compounds. Therefore the development of new strategies for the implementation of effective and safe agricultural chemicals has become more important in recent years. This could be achieved in the form of controlled-release formulation specially based on polysaccharides. These formulations not only release the active compound in a slow manner but also after degradation increase the crop output besides proving the water-holding capacity of the soil. Release systems decrease the amount of active ingredient available for leaching and volatilization. These formulations will control the environment, ecosystem and health hazards caused by the conventional pesticide formulations. Hence, these polysaccharidebased formulations could be utilized for the safe management of agrochemicals which will decrease their toxic effects and helpful for their better delivery to the field. 
Acknowledgments The authors would like to thank the following Brazilian funding agencies: FAPESP, CNPq, CAPES, and FUNDUNESP.

Conflict of interest The authors declare that there are no conflicts of interest.

\section{References}

Abd El-Mohdy HL (2007) Water sorption behavior of CMC/PAM hydrogels prepared by $\gamma$-irradiation and release of potassium nitrate as agrochemical. React Funct Polym 67:1094-1102. doi:10.1016/j. reactfunctpolym.2007.07.002

Abd El-Rehim HA (2006) Characterization and possible agricultural application of polyacrylamide/sodium alginate crosslinked hydrogels prepared by ionizing radiation. J Appl Polym Sci 101: 3572-3580. doi:10.1002/app.22487

Abhilash PC, Singh N (2009) Pesticide use and application: an Indian scenario. J Hazard Mater 165:1-12. doi:10.1016/j.jhazmat.2008.10. 061

Ahmed RZ, Siddiqui K, Arman M, Ahmed N (2012) Characterization of high molecular weight dextran produced by Weissella cibaria CMGDEX3. Carbohydr Polym 90:441-446. doi:10.1016/j. carbpol.2012.05.063

Akar E, Altınıșık A, Seki Y (2012) Preparation of pH- and ionic-strength responsive biodegradable fumaric acid crosslinked carboxymethyl cellulose. Carbohydr Polym 90:1634-1641. doi:10.1016/j.carbpol. 2012.07.043

Akelah A (1996) Novel utilizations of conventional agrochemicals by controlled release formulations. Mater Sci Eng C 4:83-98. doi:10. 1016/0928-4931(96)00133-6

Akhter J, Mahmood K, Malik KA et al (2004) Effects of hydrogel amendment on water storage of sandy loam and loam soils and seedling growth of barley, wheat and chickpea. Plant Soil Environ 50:463-469

Alves NM, Mano JF (2008) Chitosan derivatives obtained by chemical modifications for biomedical and environmental applications. Int $\mathrm{J}$ Biol Macromol 43:401-414. doi:10.1016/j.ijbiomac.2008.09.007

Andrianov, Payne (1998) Polymeric carriers for oral uptake of microparticulates. Adv Drug Deliv Rev 34:155-170

Anton N, Benoit J-P, Saulnier P (2008) Design and production of nanoparticles formulated from nano-emulsion templates-a review. J Control Release Off J Control Release Soc 128:185-199. doi:10. 1016/j.jconrel.2008.02.007

Aouada FA, de Moura MR, Orts WJ, Mattoso LHC (2010) Polyacrylamide and methylcellulose hydrogel as delivery vehicle for the controlled release of paraquat pesticide. J Mater Sci 45:49774985. doi:10.1007/s10853-009-4180-6

Azeem B, KuShaari K, Man ZB et al (2014) Review on materials \& methods to produce controlled release coated urea fertilizer. J Control Release 181:11-21. doi:10.1016/j.jconrel.2014.02.020

Azwa ZN, Yousif BF, Manalo AC, Karunasena W (2013) A review on the degradability of polymeric composites based on natural fibres. Mater Des 47:424 442. doi:10.1016/j.matdes.2012.11.025

Bajpai AK, Giri A (2002) Swelling dynamics of a ternary interpenetrating polymer network (ipn) and controlled release of potassium nitrate as a model agrochemical. J Macromol Sci A 39:75-102. doi:10.1081/ MA-120006520

Bajpai A, Giri A (2003) Water sorption behaviour of highly swelling (carboxy methylcellulose-g-polyacrylamide) hydrogels and release of potassium nitrate as agrochemical. Carbohydr Polym 53:271279. doi:10.1016/S0144-8617(03)00071-7
Bajpai SK, Sharma S (2004) Investigation of swelling/degradation behaviour of alginate beads crosslinked with $\mathrm{Ca}^{2+}$ and $\mathrm{Ba}^{2+}$ ions. React Funct Polym 59:129-140. doi:10.1016/j.reactfunctpolym. 2004.01.002

Bansode SS, Banarjee SK, Gaikwad DD et al (2010) Microencapsulation: a review. Int J Pharm Sci Rev Res 1:38-43

Baur JR (1980) Release characteristics of starch xanthide herbicide formulations. J Environ Qual 9:379. doi:10.2134/jeq1980. 00472425000900030010x

Bayarri M, Oulahal N, Degraeve P, Gharsallaoui A (2014) Properties of lysozyme/low methoxyl (LM) pectin complexes for antimicrobial edible food packaging. J Food Eng 131:18-25. doi:10.1016/j. jfoodeng.2014.01.013

Beneke CE, Viljoen AM, Hamman JH (2009) Polymeric plant-derived excipients in drug delivery. Molecules 14:2602-2620. doi:10.3390/ molecules 14072602

Ben-Hur M, Keren R (1997) Polymer effects on water infiltration and soil aggregation. Soil Sci Soc Am J 61:565. doi:10.2136/sssaj1997. $03615995006100020028 x$

Benita S (2005) Microencapsulation: methods and industrial applications, Second edn. CRC Press

Bergaya F, Lagaly G, Bergaya F, Lagaly G (2013) Handbook of clay science. Part B. Elsevier, Amsterdam

Birch CPD, Shaw MW (1997) When can reduced doses and pesticide mixtures delay the build-up of pesticide resistance? A mathematical model. J Appl Ecol 34:1032-1042. doi:10.2307/2405292

Bortolin A, Aouada FA, de Moura MR et al (2012) Application of polysaccharide hydrogels in adsorption and controlled-extended release of fertilizers processes. J Appl Polym Sci 123:2291-2298. doi:10.1002/app.34742

Bortolin A, Aouada FA, Mattoso LHC, Ribeiro C (2013) Nanocomposite PAAm/methyl cellulose/montmorillonite hydrogel: evidence of synergistic effects for the slow release of fertilizers. J Agric Food Chem 61:7431-7439. doi:10.1021/jf401273n

Bouranis DL, Theodoropoulos AG, Drossopoulos JB (1995) Designing synthetic polymers as soil conditioners. Commun Soil Sci Plant Anal 26:1455-1480. doi:10.1080/00103629509369384

Britto MAFO, Nascimento CS Jr, dos Santos HF (2004) Structural analysis of cyclodextrins: a comparative study of classical and quantum mechanical methods. Quím Nova 27:882-888. doi:10. 1590/S0100-40422004000600008

Campos EVR, de Oliveira JL, Fraceto LF (2014) Applications of controlled release systems for fungicides, herbicides, acaricides, nutrients, and plant growth hormones: a review. Adv Sci Eng Med 6: 373-387. doi:10.1166/asem.2014.1538

Celis R, Adelino MA, Hermosín MC, Cornejo J (2012) Montmorillonitechitosan bionanocomposites as adsorbents of the herbicide clopyralid in aqueous solution and soil/water suspensions. J Hazard Mater 209-210:67-76. doi:10.1016/j.jhazmat.2011.12.074

Chowdhury MA (2014) The controlled release of bioactive compounds from lignin and lignin-based biopolymer matrices. Int J Biol Macromol 65:136-147. doi:10.1016/j.ijbiomac.2014.01.012

Cini N, Tulun T, Blanck C et al (2012) Slow complexation dynamics between linear short polyphosphates and polyallylamines: analogies with "layer-by-layer" deposits. Phys Chem Chem Phys 14:30483056. doi:10.1039/c2cp23570f

Dailey OD (2004) Volatilization of alachlor from polymeric formulations. J Agric Food Chem 52:6742-6746. doi:10.1021/jf040034g

De Carvalho LB, de Alves Pinto LM (2012) Formation of inclusion complexes and controlled release of atrazine using free or silicaanchored beta-cyclodextrin. J Incl Phenom Macrocycl Chem 74: 375-381. doi:10.1007/s10847-012-0125-9

De Cicco F, Reverchon E, Adami R et al (2014) In situ forming antibacterial dextran blend hydrogel for wound dressing: SAA technology vs. spray drying. Carbohydr Polym 101:1216-1224. doi:10.1016/j. carbpol.2013.10.067 
Denardin CC, da Silva LP (2009) Starch granules structure and its regards with physicochemical properties. Ciênc Rural 39:945-954. doi:10. 1590/S0103-84782009005000003

Dixon JB (1991) Roles of clays in soils. Appl Clay Sci 5:489-503. doi: 10.1016/0169-1317(91)90019-6

dos Silva MS, Cocenza DS, Grillo R et al (2011) Paraquat-loaded alginate/chitosan nanoparticles: preparation, characterization and soil sorption studies. J Hazard Mater 190:366-374. doi:10.1016/j. jhazmat.2011.03.057

El Bahri Z, Taverdet J-L (2007) Elaboration and characterisation of microparticles loaded by pesticide model. Powder Technol 172: 30-40. doi:10.1016/j.powtec.2006.10.036

El-Sawy NM, Abd El-Rehim HA, Elbarbary AM, Hegazy E-SA (2010) Radiation-induced degradation of chitosan for possible use as a growth promoter in agricultural purposes. Carbohydr Polym 79: 555-562. doi:10.1016/j.carbpol.2009.09.002

Ertesvåg H, Valla S (1998) Biosynthesis and applications of alginates. Polym Degrad Stab 59:85-91. doi:10.1016/S0141-3910(97) 00179-1

Esposito F, Del Nobile MA, Mensitieri G, Nicolais L (1996) Water sorption in cellulose-based hydrogels. J Appl Polym Sci 60:24032407. doi:10.1002/(SICI)1097-4628(19960627)60:13<2403::AIDAPP12>3.0.CO;2-5

Feng B-H, Peng L-F (2012) Synthesis and characterization of carboxymethyl chitosan carrying ricinoleic functions as an emulsifier for azadirachtin. Carbohydr Polym 88:576-582. doi:10.1016/j. carbpol.2012.01.002

Fernandes C, Encarnação I, Gaspar A et al (2014) Influence of hydroxypropyl-cyclodextrin on the photostability of fungicide pyrimethanil. Int J Photoenergy 2014:1-8. doi:10.1155/2014/489873

Fernández-Pérez M (2007) Controlled release systems to prevent the agroenvironmental pollution derived from pesticide use. J Environ Sci Health B 42:857-862. doi:10.1080/03601230701555138

Fernández-Pérez M, González-Pradas E, Villafranca-Sánchez M, FloresCéspedes F (2000) Mobility of isoproturon from an alginatebentonite controlled release formulation in layered soil. Chemosphere 41:1495-1501

Fernández-Pérez M, González-Pradas E, Villafranca-Sánchez M, FloresCéspedes F (2001) Mobility of atrazine from alginate-bentonite controlled release formulations in layered soil. Chemosphere 43: 347-353

Fernandez-Urrusuno R, Gines JM, Morillo E (2000) Development of controlled release formulations of alachlor in ethylcellulose. $\mathrm{J}$ Microencapsul 17:331-342. doi:10.1080/026520400288300

Ferreira Almeida P, Almeida AJ (2004) Cross-linked alginate-gelatine beads: a new matrix for controlled release of pindolol. J Control Release Off J Control Release Soc 97:431-439. doi:10.1016/j. jconrel.2004.03.015

Flores Céspedes F, Villafranca Sánchez M, Pérez García S, Fernández Pérez M (2007) Modifying sorbents in controlled release formulations to prevent herbicides pollution. Chemosphere 69:785-794. doi:10.1016/j.chemosphere.2007.05.005

Flores Céspedes F, Pérez García S, Villafranca Sánchez M, Fernández Pérez M (2013) Bentonite and anthracite in alginate-based controlled release formulations to reduce leaching of chloridazon and metribuzin in a calcareous soil. Chemosphere 92:918-924. doi:10. 1016/j.chemosphere.2013.03.001

Flores-Céspedes F, Daza-Fernández I, Villafranca-Sánchez M, Fernández-Pérez M (2009) Use of ethylcellulose to control chlorsulfuron leaching in a calcareous soil. J Agric Food Chem 57:2856-2861. doi:10.1021/j9004093

Fonteno WC, Bilderback TE (1993) Impact of hydrogel on physical properties of coarse-structured horticultural substrates. J Am Soc Hortic Sci 118:217-222

Foy CL, Pritchard DW (1996) Pesticide formulation and adjuvant technology. CRC Press
Frederiksen HK, Hansen HCB, Borggaard O, Pedersen M (2002) Starchencapsulated chlorpyrifos: release rate, insecticidal activity and degradation in soil. J Microencapsul 19:319-331. doi:10.1080/ 02652040110105364

Garrido J, Cagide F, Melle-Franco M et al (2014) Microencapsulation of herbicide MCPA with native $\beta$-cyclodextrin and its methyl and hydroxypropyl derivatives: an experimental and theoretical investigation. J Mol Struct 1061:76-81. doi:10.1016/j.molstruc.2013.12.067

Ge X, He J, Qi F et al (2011) Inclusion complexation of chloropropham with $\beta$-cyclodextrin: preparation, characterization and molecular modeling. Spectrochim Acta A Mol Biomol Spectrosc 81:397403. doi:10.1016/j.saa.2011.06.028

Geng B, Jin Z, Li T, Qi X (2009) Preparation of chitosan-stabilized Fe(0) nanoparticles for removal of hexavalent chromium in water. Sci Total Environ 407:4994-5000. doi:10.1016/j.scitotenv.2009.05.051

George M, Abraham TE (2006) Polyionic hydrocolloids for the intestinal delivery of protein drugs: alginate and chitosan - a review. J Control Release Off J Control Release Soc 114:1-14. doi:10.1016/j.jconrel. 2006.04.017

Gogos A, Knauer K, Bucheli TD (2012) Nanomaterials in plant protection and fertilization: current state, foreseen applications, and research priorities. J Agric Food Chem 60:9781-9792. doi:10.1021/ jf302154y

Grillo R, dos Santos NZP, Maruyama CR et al (2012) Poly(عcaprolactone)nanocapsules as carrier systems for herbicides: physico-chemical characterization and genotoxicity evaluation. J Hazard Mater 231-232:1-9. doi:10.1016/j.jhazmat.2012.06.019

Grillo R, Pereira AES, Nishisaka CS et al (2014) Chitosan/ tripolyphosphate nanoparticles loaded with paraquat herbicide: an environmentally safer alternative for weed control. J Hazard Mater 278:163-171. doi:10.1016/j.jhazmat.2014.05.079

Guan H, Chi D, Yu J, Li X (2008) A novel photodegradable insecticide: preparation, characterization and properties evaluation of nanoImidacloprid. Pestic Biochem Physiol 92:83-91. doi:10.1016/j. pestbp.2008.06.008

Guan H, Chi D, Yu J, Li H (2011) Encapsulated ecdysone by internal gelation of alginate microspheres for controlling its release and photostability. Chem Eng J 168:94-101. doi:10.1016/j.cej.2010.12.040

Han X, Chen S, Hu X (2009) Controlled-release fertilizer encapsulated by starch/polyvinyl alcohol coating. Desalination 240:21-26. doi:10. 1016/j.desal.2008.01.047

Hassani LN, Hendra F, Bouchemal K (2012) Auto-associative amphiphilic polysaccharides as drug delivery systems. Drug Discov Today 17:608-614. doi:10.1016/j.drudis.2012.01.016

Hemvichian K, Chanthawong A, Suwanmala P (2014) Synthesis and characterization of superabsorbent polymer prepared by radiationinduced graft copolymerization of acrylamide onto carboxymethyl cellulose for controlled release of agrochemicals. Radiat Phys Chem 103:167-171. doi:10.1016/j.radphyschem.2014.05.064

Hickey J, Burke NAD, Stöver HDH (2011) Layer-by-layer deposition of clay and a polycation to control diffusive release from polyurea microcapsules. J Membr Sci 369:68-76. doi:10.1016/j.memsci. 2010.11.047

Higueras L, López-Carballo G, Cerisuelo JP et al (2013) Preparation and characterization of chitosan/HP- $\beta$-cyclodextrins composites with high sorption capacity for carvacrol. Carbohydr Polym 97:262268. doi:10.1016/j.carbpol.2013.04.007

Higueras L, López-Carballo G, Gavara R, Hernández-Muñoz P (2014) Incorporation of hydroxypropyl- $\beta$-cyclodextrins into chitosan films to tailor loading capacity for active aroma compound carvacrol. Food Hydrocoll. doi: 10.1016/j.foodhyd.2014.07.017

Hoffman AS (2012) Hydrogels for biomedical applications. Adv Drug Deliv Rev 64(Supplement):18-23. doi:10.1016/j.addr.2012.09.010

Ișıklan N (2007) Controlled release study of carbaryl insecticide from calcium alginate and nickel alginate hydrogel beads. J Appl Polym Sci 105:718-725. doi:10.1002/app.26078 
Jana T, Roy BC, Maiti S (2001) Biodegradable film: 6. Modification of the film for control release of insecticides. Eur Polym J 37:861-864. doi:10.1016/S0014-3057(00)00184-1

Jerobin J, Sureshkumar RS, Anjali CH et al (2012) Biodegradable polymer based encapsulation of neem oil nanoemulsion for controlled release of Aza-A. Carbohydr Polym 90:1750-1756. doi:10.1016/j. carbpol.2012.07.064

Johnson MS (1984) Effect of soluble salts on water absorption by gelforming soil conditioners. J Sci Food Agric 35:1063-1066. doi:10. $1002 /$ jsfa.2740351004

Johnson RM, Pepperman AB (1998) Release of atrazine and alachlor from clay-oxamide controlled-release formulations. Pestic Sci 53: 233-240. doi:10.1002/(SICI)1096-9063(199807)53:3<233::AIDPS769>3.0.CO;2-Z

Kay-Shoemake JL, Watwood ME, Lentz RD, Sojka RE (1998) Polyacrylamide as an organic nitrogen source for soil microorganisms with potential effects on inorganic soil nitrogen in agricultural soil. Soil Biol Biochem 30:1045-1052. doi:10.1016/S00380717(97)00250-2

Kay-Shoemake JL, Watwood ME, Sojka RE, Lentz RD (2000) Soil amidase activity in polyacrylamide-treated soils and potential activity toward common amide-containing pesticides. Biol Fertil Soils 31:183-186. doi:10.1007/s003740050643

Kenawy E-R (1998) Recent advances in controlled release of agrochemicals. J Macromol Sci C Polym Rev 38:365-390. doi:10.1080/ 15583729808546028

Kim YJ, Park HG, Yang YL et al (2005) Multifunctional drug delivery system using starch-alginate beads for controlled release. Biol Pharm Bull 28:394-397

Kulkarni AR, Soppimath KS, Aminabhavi TM et al (2000) Glutaraldehyde crosslinked sodium alginate beads containing liquid pesticide for soil application. J Control Release Off J Control Release Soc 63:97-105

Kulkarni AR, Soppimath KS, Aminabhavi TM, Dave AM (2002) Polymeric sodium alginate interpenetrating network beads for the controlled release of chlorpyrifos. J Appl Polym Sci 85:911-918. doi:10.1002/app.10364

Kumar J, Nisar K, Shakil NA, Sharma R (2010) Residue and bio-efficacy evaluation of controlled release formulations of metribuzin against weeds in wheat. Bull Environ Contam Toxicol 85:357-361. doi:10. 1007/s00128-010-0091-0

Kumar S, Bhanjana G, Sharma A et al (2014) Synthesis, characterization and on field evaluation of pesticide loaded sodium alginate nanoparticles. Carbohydr Polym 101:1061-1067. doi:10.1016/j.carbpol. 2013.10.025

Kumbar SG, Kulkarni AR, Dave AM, Aminabhavi TM (2001) Encapsulation efficiency and release kinetics of solid and liquid pesticides through urea formaldehyde crosslinked starch, guar gum, and starch + guar gum matrices. J Appl Polym Sci 82:28632866. doi:10.1002/app.2141

Lao S-B, Zhang Z-X, Xu H-H, Jiang G-B (2010) Novel amphiphilic chitosan derivatives: synthesis, characterization and micellar solubilization of rotenone. Carbohydr Polym 82:1136-1142. doi:10. 1016/j.carbpol.2010.06.044

Laranjeira MCM, de Fávere VT (2009) Chitosan: functional byopolymer with biomedical industrial potential. Quím Nova 32:672-678. doi: $10.1590 / \mathrm{S} 0100-40422009000300011$

Laycock BG, Halley PJ (2014) Chapter 14 - starch applications: state of market and new trends. In: Avérous PJH (ed) Starch Polym. Elsevier, Amsterdam, pp 381-419

Lentz RD, Sojka RE (1994) Field results using polyacrylamide to manage furrow erosion and infiltration. Soil Sci 158:274-282

Lertsutthiwong P, Noomun K, Jongaroonngamsang N et al (2008) Preparation of alginate nanocapsules containing turmeric oil. Carbohydr Polym 74:209-214. doi:10.1016/j.carbpol.2008. 02.009
Liu Z, Jiao Y, Wang Y et al (2008) Polysaccharides-based nanoparticles as drug delivery systems. Adv Drug Deliv Rev 60:1650-1662. doi:10. 1016/j.addr.2008.09.001

Liu H, Cai X, Wang Y, Chen J (2011) Adsorption mechanism-based screening of cyclodextrin polymers for adsorption and separation of pesticides from water. Water Res 45:3499-3511. doi:10.1016/j. watres.2011.04.004

Lv Y, Yang F, Li X et al (2014) Formation of heat-resistant nanocapsules of jasmine essential oil via gelatin/gum arabic based complex coacervation. Food Hydrocoll 35:305-314. doi:10.1016/j.foodhyd.2013. 06.003

Mateen R, Hoare T (2014) Injectable, in situ gelling, cyclodextrin-dextran hydrogels for the partitioning-driven release of hydrophobic drugs. J Mater Chem B 2:5157-5167. doi:10.1039/c4tb00631c

Mishra B, Patel BB, Tiwari S (2010) Colloidal nanocarriers: a review on formulation technology, types and applications toward targeted drug delivery. Nanomedicine Nanotechnol Biol Med 6:9-24. doi:10. 1016/j.nano.2009.04.008

Mogul MG, Akin H, Hasirci N et al (1996) Controlled release of biologically active agents for purposes of agricultural crop management. Resour Conserv Recycl 16:289-320. doi:10.1016/0921-3449(95) 00063-1

Mohanty B, Bohidar HB (2003) Systematic of alcohol-induced simple coacervation in aqueous gelatin solutions. Biomacromolecules 4: 1080-1086. doi:10.1021/bm0340801

Mørch YA, Donati I, Strand BL, Skjåk-Braek G (2006) Effect of Ca2+, $\mathrm{Ba} 2+$, and $\mathrm{Sr} 2+$ on alginate microbeads. Biomacromolecules 7: 1471-1480. doi:10.1021/bm060010d

Morin-Crini N, Crini G (2013) Environmental applications of waterinsoluble $\beta$-cyclodextrin-epichlorohydrin polymers. Prog Polym Sci 38:344-368. doi:10.1016/j.progpolymsci.2012.06.005

Nair R, Varghese SH, Nair BG et al (2010) Nanoparticulate material delivery to plants. Plant Sci 179:154-163. doi:10.1016/j.plantsci. 2010.04.012

Ni B, Liu M, Lü S (2009) Multifunctional slow-release urea fertilizer from ethylcellulose and superabsorbent coated formulations. Chem Eng J 155:892-898. doi:10.1016/j.cej.2009. 08.025

Niu Y, Li H (2012) Controlled release of urea encapsulated by starch-gpoly(vinyl acetate). Ind Eng Chem Res 51:12173-12177. doi:10. $1021 /$ ie $301684 \mathrm{p}$

Otey FH, Trimnell D, Westhoff RP, Shasha BS (1984) Starch matrix for controlled release of urea fertilizer. J Agric Food Chem 32:10951098. doi:10.1021/jf00125a041

Pacioni NL, Veglia AV (2007) Determination of poorly fluorescent carbamate pesticides in water, bendiocarb and promecarb, using cyclodextrin nanocavities and related media. Anal Chim Acta 583:63-71. doi:10.1016/j.aca.2006.10.010

Paradelo M, Soto-Gómez D, Pérez-Rodríguez P et al (2014) Predicting release and transport of pesticides from a granular formulation during unsaturated diffusion in porous media. J Contam Hydrol 158:14-22. doi:10.1016/j.jconhyd.2013.10.009

Paula HCB, Sombra FM, Abreu FOMS, de Paul RCM (2010) Lippia sidoides essential oil encapsulation by angico gum/chitosan nanoparticles. J Braz Chem Soc 21:2359-2366. doi:10.1590/S010350532010001200025

Pepperman AB, Kuan J-CW (1993) Slow release formulations of metribuzin based on alginate-kaolin-linseed oil. J Control Release 26:21-30. doi:10.1016/0168-3659(93)90205-J

Pepperman AB, Kuan J-CW (1995) Controlled release formulations of alachlor based on calcium alginate. J Control Release 34:17-23. doi: 10.1016/0168-3659(94)00111-7

Pérez-Martínez JI, Morillo E, Ginés JM (1999) $\beta$-CD effect on 2,4-D soil adsorption. Chemosphere 39:2047-2056. doi:10.1016/S00456535(99)00093-4 
Petruccioli M, Raviv M, Di Silvestro R, Dinelli G (2011) 6.42 - agriculture and agro-industrial wastes, byproducts, and wastewaters: origin, characteristics, and potential in bio-based-compounds production. In: Moo-Young M (ed) Compr. Biotechnol. Second Ed. Academic Press, Burlington, pp 531-545

Pfister G, Bahadir M, Korte F (1986) Release characteristics of herbicides from $\mathrm{Ca}$ alginate gel formulations. J Control Release 3:229-233. doi:10.1016/0168-3659(86)90094-5

Popp J, Pető K, Nagy J (2013) Pesticide productivity and food security. A review. Agron Sustain Dev 33:243-255. doi:10.1007/s13593-0120105-x

Prajapati VD, Maheriya PM, Jani GK, Solanki HK (2014) Carrageenan: a natural seaweed polysaccharide and its applications. Carbohydr Polym 105:97-112. doi:10.1016/j.carbpol.2014.01.067

Price R, Poursaid A, Ghandehari H (2014) Controlled release from recombinant polymers. J Control Release 190:304-313. doi:10. 1016/j.jconrel.2014.06.016

Puoci F, Iemma F, Spizzirri UG et al (2008) Polymer in agriculture: a review. Am J Agric Biol Sci 3:299

Qian K, Shi T, He S et al (2013) Release kinetics of tebuconazole from porous hollow silica nanospheres prepared by miniemulsion method. Microporous Mesoporous Mater 169:1-6. doi:10.1016/j. micromeso.2012.10.017

Qiu Y, Park K (2001) Environment-sensitive hydrogels for drug delivery. Adv Drug Deliv Rev 53:321-339. doi:10.1016/S0169-409X(01) 00203-4

Qiu Y, Park K (2012) Environment-sensitive hydrogels for drug delivery. Adv Drug Deliv Rev 64(Supplement):49-60. doi:10.1016/j.addr. 2012.09.024

Qiu X, Tao S, Ren X, Hu S (2012) Modified cellulose films with controlled permeatability and biodegradability by crosslinking with toluene diisocyanate under homogeneous conditions. Carbohydr Polym 88:1272-1280. doi:10.1016/j.carbpol.2012. 02.007

Quiñones JP, García YC, Curiel H, Covas CP (2010) Microspheres of chitosan for controlled delivery of brassinosteroids with biological activity as agrochemicals. Carbohydr Polym 80:915-921. doi:10. 1016/j.carbpol.2010.01.006

Raafat AI, Eid M, El-Arnaouty MB (2012) Radiation synthesis of superabsorbent $\mathrm{CMC}$ based hydrogels for agriculture applications. Nucl Instrum Meth Phys Res Sect B-Beam Interact Mater At 283:71-76. doi:10.1016/j.nimb.2012.04.011

Raemdonck K, Martens TF, Braeckmans K et al (2013) Polysaccharidebased nucleic acid nanoformulations. Adv Drug Deliv Rev 65: 1123-1147. doi:10.1016/j.addr.2013.05.002

Rashidzadeh A, Olad A, Salari D, Reyhanitabar A (2014) On the preparation and swelling properties of hydrogel nanocomposite based on Sodium alginate-g-Poly (acrylic acid-co-acrylamide)/Clinoptilolite and its application as slow release fertilizer. J Polym Res 21:1-15. doi:10.1007/s10965-013-0344-9

Rodrigues DC, Caceres CA, Ribeiro HL et al (2014) Influence of cassava starch and carnauba wax on physical properties of cashew tree gumbased films. Food Hydrocoll 38:147-151. doi:10.1016/j.foodhyd. 2013.12.010

Roy A, Bajpai J, Bajpai AK (2009) Dynamics of controlled release of chlorpyrifos from swelling and eroding biopolymeric microspheres of calcium alginate and starch. Carbohydr Polym 76:222-231. doi: 10.1016/j.carbpol.2008.10.013

Roy A, Singh SK, Bajpai J, Bajpai AK (2014) Controlled pesticide release from biodegradable polymers. Cent Eur J Chem 12:453469. doi:10.2478/s11532-013-0405-2

Rudzinski WE, Dave AM, Vaishnav UH et al (2002) Hydrogels as controlled release devices in agriculture. Des Monomers Polym 5: 39-65. doi:10.1163/156855502760151580

Rutz JK, Zambiazi RC, Borges CD et al (2013) Microencapsulation of purple Brazilian cherry juice in xanthan, tara gums and xanthan-tara hydrogel matrixes. Carbohydr Polym 98:1256-1265. doi:10.1016/j. carbpol.2013.07.058

Sadeghi M, Hosseinzadeh H (2008) Synthesis of starchPoly(Sodium Acrylate-co-Acrylamide) superabsorbent hydrogel with salt and $\mathrm{pH}$-responsiveness properties as a drug delivery system. J Bioact Compat Polym 23:381-404. doi: 10.1177/0883911508093504

Sahoo S, Manjaiah KM, Datta SC et al (2014) Kinetics of metribuzin release from bentonite-polymer composites in water. J Environ Sci Health B 49:591-600. doi:10.1080/03601234.2014.911578

Sannino A, Esposito A, De Rosa A et al (2003) Biomedical application of a superabsorbent hydrogel for body water elimination in the treatment of edemas. J Biomed Mater Res A 67:1016-1024. doi:10. 1002/jbm.a.10149

Schaffazick SR, Guterres SS, de Freitas LL, Pohlmann AR (2003) Caracterização e estabilidade físico-química de sistemas poliméricos nanoparticulados para administração de fármacos. Quím Nova 26:726-737

Scher HB (1999) Controlled-release delivery systems for pesticides. CRC Press

Schreiber MM, White MD, Wing RE et al (1988) Bioactivity of controlled release formulations of starch-encapsulated EPTC. J Control Release 7:237-242. doi:10.1016/0168-3659(88)90056-9

Senel S, McClure SJ (2004) Potential applications of chitosan in veterinary medicine. Adv Drug Deliv Rev 56:1467-1480. doi:10.1016/j. addr.2004.02.007

Sharma R, Bajpai J, Bajpai AK et al (2014) Designing slow waterreleasing alginate nanoreserviors for sustained irrigation in scanty rainfall areas. Carbohydr Polym 102:513-520. doi:10.1016/j. carbpol.2013.11.059

Shasha BS, Trimnell D, Otey FH (1981) Encapsulation of pesticides in a starch-calcium adduct. J Polym Sci Polym Chem Educ 19:18911899. doi:10.1002/pol.1981.170190803

Shukla PG, Rajagopalan N, Bhaskar C, Sivaram S (1991) Crosslinked starch-urea formaldehyde (St-UF) as a hydrophilic matrix for encapsulation: studies in swelling and release of carbofuran. J Control Release 15:153-165. doi:10.1016/0168-3659(91)90073-M

Singh B, Sharma DK, Gupta A (2007) Controlled release of thiram fungicide from starch-based hydrogels. J Environ Sci Health B 42: 677-695. doi:10.1080/10934520701244482

Singh B, Sharma DK, Gupta A (2008) In vitro release dynamics of thiram fungicide from starch and poly(methacrylic acid)-based hydrogels. J Hazard Mater 154:278-286. doi:10.1016/j.jhazmat.2007.10.024

Singh B, Sharma DK, Gupta A (2009a) A study towards release dynamics of thiram fungicide from starch-alginate beads to control environmental and health hazards. J Hazard Mater 161:208-216. doi:10. 1016/j.jhazmat.2008.03.074

Singh B, Sharma DK, Gupta A (2009b) The controlled and sustained release of a fungicide from starch and alginate beads. J Environ Sci Health B 44:113-122. doi:10.1080/03601230802599019

Singh B, Sharma DK, Kumar R, Gupta A (2009c) Controlled release of the fungicide thiram from starch-alginate-clay based formulation. Appl Clay Sci 45:76-82. doi:10.1016/j.clay.2009.03.001

Singh B, Sharma DK, Kumar R, Gupta A (2010a) Controlled release of thiram from neem-alginate-clay based delivery systems to manage environmental and health hazards. Appl Clay Sci 47:384-391. doi: 10.1016/j.clay.2009.12.001

Singh B, Sharma DK, Kumar R, Gupta A (2010b) Development of a new controlled pesticide delivery system based on neem leaf powder. J Hazard Mater 177:290-299. doi:10.1016/j. jhazmat.2009.12.031

Singh B, Sharma DK, Dhiman A (2013) Environment friendly agar and alginate-based thiram delivery system. Toxicol Environ Chem 95: 567-578. doi:10.1080/02772248.2013.801976

Sojka RE, Lentz RD, Westermann DT (1998) Water and erosion management with multiple applications of polyacrylamide in furrow 
irrigation. Soil Sci Soc Am J 62:1672. doi:10.2136/sssaj1998. $03615995006200060027 \mathrm{x}$

Sopeña F, Cabrera A, Maqueda C, Morillo E (2005) Controlled release of the herbicide norflurazon into water from ethylcellulose formulations. J Agric Food Chem 53:3540 3547. doi:10.1021/jf048007d

Sopeña F, Maqueda C, Morillo E (2007) Norflurazon mobility, dissipation, activity, and persistence in a sandy soil as influenced by formulation. J Agric Food Chem 55:3561-3567. doi:10.1021/ jf070064u

Sopeña F, Villaverde J, Maqueda C, Morillo E (2011) Photostabilization of the herbicide norflurazon microencapsulated with ethylcellulose in the soil-water system. J Hazard Mater 195:298-305. doi:10.1016/ j.jhazmat.2011.08.039

Soppimath KS, Aminabhavi TM, Kulkarni AR, Rudzinski WE (2001) Biodegradable polymeric nanoparticles as drug delivery devices. J Control Release 70:1-20. doi:10.1016/S0168-3659(00)00339-4

Swinnen JFM, de Gorter H, Rausser GC, Banerjee AN (2000) The political economy of public research investment and commodity policies in agriculture: an empirical study. Agric Econ 22:111-122. doi:10.1016/S0169-5150(99)00050-X

Tao S, Pang R, Chen C et al (2012) Synthesis, characterization and slow release properties of $O$-naphthylacetyl chitosan. Carbohydr Polym 88:1189-1194. doi:10.1016/j.carbpol.2012.01.076

Tefft J, Friend DR (1993) Controlled release herbicide formulations based on polymeric microspheres. J Control Release 27:27-35. doi:10. 1016/0168-3659(93)90054-9

Terada Y, Yanase M, Takata H et al (1997) Cyclodextrins are not the major cyclic $\alpha-1,4$-glucans produced by the initial action of cyclodextrin glucanotransferase on amylose. J Biol Chem 272:1572915733. doi:10.1074/jbc.272.25.15729

Trimnell D, Shasha BS, Otey FH (1985) The effect of $\alpha$-amylases upon the release of trifluralin encapsulated in starch. J Control Release 1: 183-190. doi:10.1016/0168-3659(85)90016-1

Tsuji K (2001) Microencapsulation of pesticides and their improved handling safety. J Microencapsul 18:137-147. doi:10.1080/ 026520401750063856

Vaughn SF, Kenar JA, Felker FC et al (2013) Evaluation of alternatives to guar gum as tackifiers for hydromulch and as clumping agents for biodegradable cat litter. Ind Crop Prod 43:798-801. doi:10.1016/j. indcrop.2012.09.002

Venkatesan P, Manavalan R, Valliappan K et al (2009) Microencapsulation: a vital technique in novel drug delivery system. J Pharm Sci Res 1:26-35

Villafranca-Sánchez M, González-Pradas E, Fernández-Pérez M et al (2000) Controlled release of isoproturon from an alginate-bentonite formulation: water release kinetics and soil mobility. Pest Manag Sci 56:749-756. doi:10.1002/1526-4998(200009)56:9<749::AIDPS196>3.0.CO;2-\#

Wanyika H (2013) Sustained release of fungicide metalaxyl by mesoporous silica nanospheres. J Nanoparticle Res. doi:10.1007/s11051013-1831-y

Wen Y, Yuan Y, Chen H et al (2010) Effect of chitosan on the enantioselective bioavailability of the herbicide dichlorprop to
Chlorella pyrenoidosa. Environ Sci Technol 44:4981-4987. doi: 10.1021/es100507p

Wen Y, Chen H, Yuan Y et al (2011) Enantioselective ecotoxicity of the herbicide dichlorprop and complexes formed with chitosan in two fresh water green algae. J Environ Monitor JEM 13:879-885. doi: 10.1039/c0em00593b

Wing RE, Otey FH (1983) Determination of reaction variables for the starch xanthide encapsulation of pesticides. J Polym Sci Polym Chem Educ 21:121-140. doi:10.1002/pol.1983.170210113

Wlodarczyk M, Siwek H (2013) Clomazone release kinetics from alginate matrix to the water environment. Przemysl Chem 92:15131516

Wong TY, Preston LA, Schiller NL (2000) ALGINATE LYASE: review of major sources and enzyme characteristics, structure-function analysis, biological roles, and applications. Annu Rev Microbiol 54:289-340. doi:10.1146/annurev.micro.54.1.289

Woodhouse J, Johnson MS (1991) Effect of superabsorbent polymers on survival and growth of crop seedlings. Agric Water Manag 20:6370. doi:10.1016/0378-3774(91)90035-H

Wu L, Liu M (2008) Preparation and properties of chitosan-coated NPK compound fertilizer with controlled-release and waterretention. Carbohydr Polym 72:240-247. doi:10.1016/j. carbpol.2007.08.020

Yang L, Yang Y, Chen Z et al (2014) Influence of super absorbent polymer on soil water retention, seed germination and plant survivals for rocky slopes eco-engineering. Ecol Eng 62:27-32. doi:10. 1016/j.ecoleng.2013.10.019

Yangyuoru M, Boateng E, Adiku SGK et al (2006) Effects of natural and synthetic soil conditioners on soil moisture retention and maize yield. West Afr J Appl Ecol. doi:10.4314/ wajae.v9i1.45676

Yoshida R, Sakai K, Okano T, Sakurai Y (1993) Pulsatile drug delivery systems using hydrogels. Adv Drug Deliv Rev 11:85-108. doi:10. 1016/0169-409X(93)90028-3

Zhang Y, Zhao Y (2007) Nonlinear dynamics of atomic force microscopy with intermittent contact. Chaos, Solitons Fractals 34:1021-1024. doi:10.1016/j.chaos.2006.03.125

Zhang M, Gao B, Chen J et al (2014a) Slow-release fertilizer encapsulated by graphene oxide films. Chem Eng J 255:107-113. doi:10. 1016/j.cej.2014.06.023

Zhang W, He S, Liu Y et al (2014b) Preparation and characterization of novel functionalized prochloraz microcapsules using silica-alginateelements as controlled release carrier materials. ACS Appl Mater Interfaces 6:11783-11790. doi:10.1021/am502541g

Zhao J, Wilkins RM (2005) Low molecular weight polylactic acid as a matrix for the delayed release of pesticides. J Agric Food Chem 53: 4076-4082. doi:10.1021/jf0480400

Zhong K, Lin Z-T, Zheng X-L et al (2013) Starch derivative-based superabsorbent with integration of water-retaining and controlledrelease fertilizers. Carbohydr Polym 92:1367-1376. doi:10.1016/j. carbpol.2012.10.030

Zhu Y, An X, Li S, Yu S (2009) Nanoencapsulation of $\beta$-cypermethrin by complex coacervation in a microemulsion. J Surfactant Deterg 12: 305-311. doi:10.1007/s11743-009-1124-8 